\title{
Functional Morphology of Lingual Protrusion in Marine Toads (Bufo marinus)
}

\author{
CARL GANS AND GERARD C. GORNIAK \\ Division of Biological Sciences, The University of Michigan, Ann Arbor, \\ Michigan 48109
}

\begin{abstract}
Bufo marinus catches its prey by stiffening the intrinsic muscles of the tongue, rapidly flipping the tongue out of the mouth. High-speed cinematography synchronized with computer-analyzed electromyograms (EMGs) shows that during the flip the tongue is supported by the M. genioglossus medialis and that this muscle stiffens into a rod when stimulated. Coincident stiffening of the transversely arranged $M$. genioglossus basalis provides a wedge under the anterior tip of this rod. Stiffening of the M. submentalis depresses the mandibular symphysis and brings the dentary tips together. The $M$. submentalis also acts on the wedge of the basalis to raise and rotate the rigid rod of the medialis over the symphysial attachment. The tip of this lingual rod carries along the pad and soft tissues of the tongue. The lingual pad, positioned in the posterodorsal portion of the resting tongue, rotates during eversion so that its dorsal surface impacts onto the prey object. Retraction starts by contraction of the elongate, parallel fibers of the M. hyoglossus; this retracts the medial sulcus of the pad and holds the prey by a suction cup-like effect. The extensibility of the buccal membranes allows the pad to be retracted first; it reaches the posterior portion of the buccal cavity before the still-rigid, backward rotating $M$. genioglossus has reached the level of the symphysis.

Protraction of the hyoid facilitates the extension of the $\mathbf{M}$. hyoglossus. The $\mathbf{M}$. sternohyoideus only retracts the hyoid and stabilizes it when the tongue starts to pull posteriorly; it does not assist tongue protrusion. The $\mathrm{Mm}$. petrohyoideus and omohyoideus show only incidental activity, and the $M$. depressor mandibulae participates in mouth opening but is not otherwise involved in the flip.

Previous hypotheses of the flipping mechanism are reviewed and evaluated.
\end{abstract}

It is well known that many frogs catch their prey with a rapid flip of the tongue, that the anterior end of this tongue is fixed and the posterior free in most species, and that the emerging tongue rotates over the mandibular symphysis. The system is curious in that the tongue of most anurans is anchored anterior to the hyoid and lacks a hard-tissue skeleton that could induce and support this rapid protrusion. The mechanism generating rotation of the tongue, as well as the manner in which the tongue grips the prey, were long accorded minimal attention, although the retrolingual surface of the frog tongue has been used in the resolution of some basic questions in muscle physiology (Biesladecki and Herzig, 1859; Fischl and Kahn, 1928; Gelfan, 1930; Pratt and Reid, 1930; Fulton and Lutz, 1940). Such standard works as Noble (1931:201) only briefly comment on the tongue mechanism, and even Böker (1937:81) only provides cursory mention.

For a long time, the hydrostatic action theory of Hartog (1901a,b), questioned by Gaupp (1901) in the same year, appeared in most textbooks of introductory zoology. In 1961, a popular article (Gans) presented an alternative muscular protrusion mechanism, as several series of photographs provided by Mr. Mervin F. Roberts, made the prevalent views questionable. A more formal functional analysis was started (Gans, 1962), but it soon became clear that any convincing decision among the

The present address of Dr. Gerard C. Gorniak is Department of
Biological Science, Florida State University, Tallahassee, FL 32306. Biological Science, Florida State University, Tallahassee,
Received August 17, 1981. Accepted November 23, 1981. 
various conflicting hypotheses in the literature must be based upon electromyographical analysis, the tools for which were then unavailable to us.

Finally, it is possible here to offer a functional analysis of the lingual flip in Bufo marinus, a toad selected because of its large size, availability, and tongue architecture (Regal and Gans, 1977); our analysis is based on medium-speed (100-400 fps) films, coupled with synchronized electromyograms. This report concentrates on the actions and movements of muscles and other tissues associated with lingual protrusion and retraction. Almost all of these muscles participate in other roles as well, and such actions are not dealt with here. Because of the widespread interest in the biology of frogs and their use in research and training in the biomedical and animal sciences, we include a brief historical summary of studies and hypotheses of the mechanism.

\section{HISTORICAL REVIEW}

It seems best to ignore some early accounts of the lingual flip, suggesting that the tongue is propelled by a jet of air passing from the glottis (refs. in Duméril and Bibron, 1841:8, 127; also Magimel-Pellonnier, 1924). The first modern discussion regarding the functional anatomy of the frog tongue was furnished by Dugès (1827), who later provided the first useful descriptive and developmental account of anuran osteology and myology (Dugès, 1834). While his descriptions of lingual myology (of various European species) were quite gross, he noted that the tongue was activated by the $\mathrm{Mm}$. hyoglossus and genioglossus, assisted by a complicated interaction with the muscles depressing the lower jaw and advancing the hyoid system. The key point, ignored for the next century, is given in his statement, "le sous-mentonnier qui, rapprochant les branches de la machoire, non-seulement les affermit, mais en rétrécit l'arc ... recourbé en bas, ce qui favorise d'autant le mecanisme cidessus indiqué."

The authors of the next 70 years (Klein, 1850; Fixsen, 1857; Wiedersheim, in Ecker, 1882; Ferdinand, 1894) concerned themselves primarily with the relative function of the $\mathrm{Mm}$. hyoglossus and genioglossus and with the description of the intralingual musculature. Furthermore, Wiedersheim (in Ecker, 1882:11) interpreted the intermaxillary gland (of the upper jaw) as mucous and stated that its secretion would be wiped off by the anteriorly passing tongue.
Three papers appeared in 1901 that were cited often and widely. The first two, respectively the original and translation of a brief note by Hartog (1901a, 1901b), note (1) that the lymphatic sublingual sinus extends into the tongue itself, and (2) that the tongue rises up and springs forward if this sinus is injected with colored cocoa butter "under pressure." Hartog maintained that contraction of the mylohyoid (M. intermandibularis posterior?) erects the tongue by shifting lymph from the posteroventral portion of the sinus to its intralingual portion; he does not discuss the origin of the lymph nor demonstrate that the volume of the posterior spaces is adequate to fill the tongue as they are emptied.

Apparently, Gaupp (1901) encountered the protrusion problem in the course of his revision of the Ecker text (1882). He relied mainly on histological sections rather than upon dissections of the area in question, and rejected "a priori" the hydrostatic mechanism as being too slow. Gaupp claimed that (1) the anterior (basal) part of the tongue is pulled forward by the pars basalis of the M. genioglossus, (2) the posterior portion of the tongue passively follows the rotation of the anterior over the mandibular symphysis, and (3) retraction is achieved primarily by the $M$. hyoglossus. The importance of the paper lies in its detailed demonstration of the topography and relations of the several muscular and lymphatic volumes. Although Gaupp (1896:138) had earlier suggested that the submentalis (sous-mentonnier of Dugès) serves to raise the mandibular symphysis during ventilation, he did not take further notice of Dugès' view that these elements could be depressed by contraction of the submentalis.

In 1924, Magimel-Pelonnier published an elegant thesis on the amphibian tongue (not cited again until 1977), reporting on the lingual anatomy and embryology of 45 species of frogs. The study is important, because it documents the existence of morphological diversity and makes clear that various kinds of frogs must differ in the way they protrude their tongues. The functional analysis, based upon direct observation, cinematography of tongue movements (in various European species), anatomy, and stimulation of the various muscles, divided the movement sequence of advanced frogs into three phases; but curiously it made no mention of the Hartog (1901a, b) hypothesis. In Magimel-Pelonnier's first phase the $M$. genioglossus is inactive, and the retracting portions of the M. hyoglossus are ac- 
tive. The anterior fold of the tongue is then pulled toward the hyal base, so that the transverse connective tissues are stretched like the string of a bow. During the second phase, the $M$. hyoglossus suddenly becomes inactive, and the genioglossus starts to fire, pulling the tongue anteriorly into a flip. In advanced species, such as members of Bufo, the flip is facilitated by folded connective tissues located anterior to the tongue pad, and by a muscular hinge formed in part by the short fibers of the $M$. genioglossus and the basal and lingual sinuses. The movable mentomeckelian bones of some species are mentioned as facilitating the rotational movement. During the third phase, the entire M. hyoglossus becomes active, pulling the lingual fibers around the prey and then retracting the tongue and prey toward the entrance of the esophagus. Different mechanisms are proposed for various primitive frogs and the proteroglossine frogs.

In 1933, Gnanamuthu described the throat musculature and tongue of two Indian frogs and reacted to Holmes' (1919, and later editions) erroneous ascription of Hartog's views to Gaupp. The "extreme rapidity" of the tongue flip allowed Gnanamuthu to make only a speculative interpretation. He concluded that (1) all fibers within the tongue appertain either to the M. genioglossus or the M. hyoglossus (i.e., there are no distinct intrinsic lingual fibers), (2) neither the intermaxillary gland nor the lymph spaces are associated with tongue propulsion, (3) the hyoid musculature per se is not involved, and (4) the hyoglossus is normally in tension and relaxes when stimulated. This relaxation (of a muscle fitting the "tonic" category) was claimed to provide a forward rebound, that serves to flip the tongue, when combined with the "upward and forward" force produced by the M. genioglossus basalis.

In a 1942 note, Barclay presented a reconstructed series from individual photographs of tongue protrusion in Bufo vulgaris. He argued briefly for a muscular rather than hydrostatic propulsive mechanism, in view of (1) the short time of protrusion $(50 \mathrm{msec}),(2)$ the absence of obvious inflation, and (3) the "constriction" visible in dorsal view when the tongue is in the fully extended position.

In 1957, Tatarinov published a preliminary report (grossly mistranslated in the U.S. version of the journal) of a survey of the lingual mechanism of 18 species of frogs. He ascribed the flipping to muscular contraction and argued that the flip is accomplished mainly by a ventral movement of the symphysial junction and of the mentomeckelian elements. He ascribed movement of this joint to contraction of the $M$. geniohyoideus (rather than the M. submentalis) and illustrated the movement with a rather diagrammatic sketch.

In 1961, Severtzov (like Tatarinov, a student of Schmalhausen) presented a more extensive paper in which he discussed the morphology and flipping mechanism of the tongue in eight species of frogs. He postulated a combined hydrostatic and muscular mechanism operating in three stages: (1) erection of the anterior portion of the tongue by contraction of the $M$. genioglossus; (2) straightening of the tongue by "manometric" injection of lymph from the posterior part of the lymphatic sinus into the tongue, and simultaneous lowering of the symphysis by contraction of the $\mathrm{Mm}$. geniohyoideus and intermandibularis (anterior = M. submentalis); and (3) the actual throwing of the tongue by action of the $M$. genioglossus.

In the same year, there appeared a popular report (Gans, 1961, also 1962), proposing (on the bases of anatomy, strobe photographs, and stimulation experiments) that the American bullfrog, Rana catesbeiana, flips the tongue by (1) contracting the doubly pinnate $\mathrm{M}$. genioglossus, thus forming a rod, and (2) rotating this rod by a mechanical couple, activated mainly by contraction of the $M$. submentalis. Action of this muscle approximates the mandibles anteromedially. As a result, the mentomeckelian bones are depressed (medially), and the attached anterior end of the M. genioglossus is lowered. Further, as the M. submentalis straightens it pushes against the middle of the M. genioglossus. The soft tissues of the lingual tip are assumed to be carried along and then to slide anteriorly by their intrinsic inertia as the rod-like $M$. genioglossus basalis rotates around its anterior end. The tongue is later retracted by action of the $M$. hyoglossus. The photographic illustrations show that the tongue does not touch the roof of the mouth during the forward flip and confirm Gnanamuthu's suggestion that the intermaxillary gland is not involved in the ingestion sequence. Independently, Francis (1961) demonstrated that the intermaxillary gland produces serous rather than sticky mucus secretions and has a role in "tasting" the food once it is in the mouth. The diagrams of the popular report have been reproduced in a number of texts, leading to the implication that the mechanism described for Rana applies to "the frog" and is therefore universal among frogs. 
In 1977 Regal and Gans, using strobe movies of feeding in phaneroglossan frogs, called attention to the diversity of lingual myology in anurans and noted that this diversity had been documented earlier by Magimel-Pelonnier (1924). They expanded the Gans model and presented various functional and phylogenetic hypotheses, specifically designed to call attention to the diversity of tongues and to the possible use of the tongue as a phylogenetic characteristic.

The same year, Emerson (1977) proposed a different model on the basis of cinefluoroscopy and muscle stimulation (but not electromyography) in Bufo marinus. According to her report, anterior movement of the hyoid, rather than the genial musculature, flips the tongue. The model involves three phases. During phase one, the Mm. sternohyoideus, geniohyoideus, and genioglossus fire, fixating the hyoid posteriorly, opening the jaws and "storing potential energy" (p. 119) in the system. During phase two, the tongue, which is then under tension, and the hyoid are allowed to move when the M. sternohyoideus becomes inactive. The anterior movement of the released hyoid then imparts "kinetic energy to the tongue to protrude it out of the mouth" (p. 119).

\section{MATERIALS AND METHODS}

The tongue flip was studied in 21 unanesthetized and unrestrained toads (Bufo marinus; snout-vent length 10-15 cm; weight 264-693 g), using high-speed cinematography and synchronized electromyography (EMG). Each toad was maintained in an individual compartment with a dish placed near its front. Toads were conditioned to take mealworms (Tenebrio sp.) dropped.in front of them while a strobe light was flashing or bright lights were turned on.

This report is based on 36 feeding sequences (from 17 toads) with good simultaneous cine and EMG, another 76 feeding sequences with only EMG, and films of more than 100 control feeding sequences in 5 unoperated animals. In three other animals the lingual and hyoid muscles were exposed under deep anesthesia, and then stimulated prior to their removal; some movements of hyoid and tongue were simultaneously filmed. The removed muscles were blotted dry, weighed, fastened to tongue depressors and placed into $10 \%$ buffered Formalin. After fixation, the muscles were placed in $30 \%$ nitric acid for 2-4 days which dissolved the connective tissues. The nitric acid was then aspirated, the muscle was placed in $50 \%$ glycerol, and the regional fiber directions were drawn under a Wild dissecting microscope with a camera lucida. Simultaneously, the lengths of the fibers were measured regionally using a millimeter ruler and ocular micrometer.

Most feeding sequences were filmed at speeds between 140 and 200 frames per second, and some at 400 frames per second, with a High Cam 16-mm high-speed cine camera (Sid Redlake Inc.). Illumination was provided by either a high-output strobe (Strobex 140) or conventional movie flood lights. A signal from the output of a photocell mounted on the feeding compartment or directly from the camera shutter mechanism was recorded on a Honeywell tape recorder to allow correlation of movements with EMG. The camera was focused on the feeding dish, and the field was large enough to include a mirror placed at $45^{\circ}$ to one side. The food was dropped before the toad and filming started when it showed intention movements.

For EMG, the toads were first anesthetized by intraperitoneal injection $(0.04 \mathrm{mg}$ per $\mathrm{g}$ body weight) of Tricaine Methanesulfonate (MS 222). Four twisted bipolar electrodes of $0.076-\mathrm{mm}$ teflon-coated stainless-steel wire (Medwire Inc., Mount Vernon, New York) with 1-mm bare ends were then implanted using 22gauge hypodermic needles (intradermal tips). The needles were passed through a $1-\mathrm{cm}$ skin incision ventral and posterior to the parotid gland, and then subcutaneously to the oral cavity; the position of each tip of the needle could be monitored by palpation of the opened mouth of the toad. Brief reverse stimulation via the electrodes during implantation helped to determine the location of the electrode tips; later, the location was verified by routine autopsy. The electrode wires were kinked several times as the needle was removed, and their free ends then soldered to a harness of earphone wire that was tied to the pelvic girdle. Recording sessions always started more than 24 hours after electrode insertion to permit recovery from anesthesia. Signals from the four EMG electrodes were amplified through $26 \mathrm{~A} 2$ Tektronix preamplifiers, monitored on a Brush 481 strip chart recorder and a Tektronix 565 oscilloscope and stored on 1-inch magnetic tape by a Honeywell 5600 medium-band 14-channel tape recorder.

The films were projected frame-by-frame with a Lafayette analytical projector and the positions of mandible and tongue sketched in reference to the contour of the entire head, eyes, nostrils, tympanum and landmarks on the feeding chamber. The control films re- 
vealed no significant change in feeding behavior as a result of electrode insertion.

Hard copy printouts of the electromyograms were first checked for the start and stop of muscular activity and for changes in relative firing amplitude. Subsequently, signals stored on tape were analyzed on 2 modified HewlettPackard 21MX minicomputer. The output of the photocell or camera shutter (reflecting the instant that the film was exposed) provided temporal cues for EMG analysis. The computer was programmed to count the number of EMG spikes from one photocell signal to the next and to determine the mean spike amplitude for that interval. The program could be started after a specified number of frames and noise were eliminated. Bar graphs of the number of spikes, the spike amplitude, and the percent of the spike numbers times the amplitude relative to the maximum value of the product during ingestion were plotted using an Tektronix 4051 graphic display unit (32K memory) and an interactive Tektronix 4662 digital plotter. The computer analysis provides information about muscular activity preceding the condition observed in each picture. The values available then sum the electrical events over the inter-picture interval with mean activity assumed to have preceded the mechanical event by one-half this time.

\section{GENERAL TOPOGRAPHIC ANATOMY}

Action of the tongue involves only the tissues of the mandibles and hyoid. This brief description of these skeletal elements serves only to orient the subsequent section on myology.

The composite mandibles are narrow and rodlike, of oval cross-section and show an overlapping of anterior and posterior elements along their middle, so that each mandible may be deformed by rotating it about its long axis. The mandibles are connected anteriorly by fairly rigid cartilages and connective tissues in the mentomeckelian region. Opening of the mouth rotates the mandibles about the quadratoarticular joint. When the mouth is closed, the lower jaws appear relatively straight in lateral view and lie in the plane of their anterior and posterior articulations. In ventral view, the mandibular arch is U-shaped and the posteriorly pointing free ends bear the articulation to the quadrate.

Much of the intermandibular space (i.e., buccal floor) is filled by the thin and wide cartilaginous hyoid (cf. Trewavas, 1933). Each side of the hyoid has four, i.e., two anterolateral and two posterolateral processes (horns and cornua), extending from each side (Fig. 2). Bufo marinus lacks an anterior process of the ceratohyal, and the rounded alar plates point toward the ceratohyal projections. The ceratohyal first passes rostrally from the body of the hyoid, then curves sharply laterally and posteriorly. Each hypobranchial extends horizontally from the body of the hyoid but then curves dorsally where the caudal limit of the posterior process shows membranous connection with the larynx.

The floor of the buccal cavity is lined by a densely reinforced mucous membrane that joins the dorsal edge of the mandibles just medial to the tooth rows. The tongue is large, fleshy, and rounded, having a widely protruding free posterior edge. The anterior portion (adjacent to the symphysis) is smooth and extensile and has a relatively thin mucous cover; the posterior two-thirds including the tip have a thickened papillose glandular mucosa that may show a medial trough. The lingual tissue appears flabby in anesthetized specimens; apparently it is shaped by muscular action.

The muscles of the tongue attach to the lower jaw and to the hyoid (Figs. 1 and 2). Multiple layers of muscles pass anteroposteriorly near the midline of the buccal floor; but lateral to the $M$. geniohyoideus, the thin layer of the $M$. intermandibularis posterior and the more posteriorly placed $\mathrm{M}$. interhyoideus are the only muscles separating buccal membranes from the gular skin. The hyoid edges and horns, underlying the mucous membranes of the oral floor, protrude into this free space.

The architecture of the medial mandibular region is most clearly seen from a sagittal section of a specimen preserved with the mouth closed (Fig. 3). Anteriorly, a short, stout, transverse muscle (M. submentalis) crosses between the mandibular tips at or below the level of the ventral mandibular edge. Superficial to it lies the dense medial aponeurosis of the thin, roughly transverse $M$. intermandibularis posterior. This sheet, and its posterior continuation as the $M$. interhyoideus, extends posteriorly to the level of the jaw joint (attachment and architecture of the posterior portion are affected by sexual dimorphism owing to the formation of vocal pouches). Deep to the intermandibular sheet lies the thin bipartite $M$. geniohyoideus passing longitudinally along the medial zone (Fig. 1B). It originates on the laryngeal fascia and posterior portion of the hyoid and inserts on muscles and skeleton of the symphysial region. Except for the M. sub- 

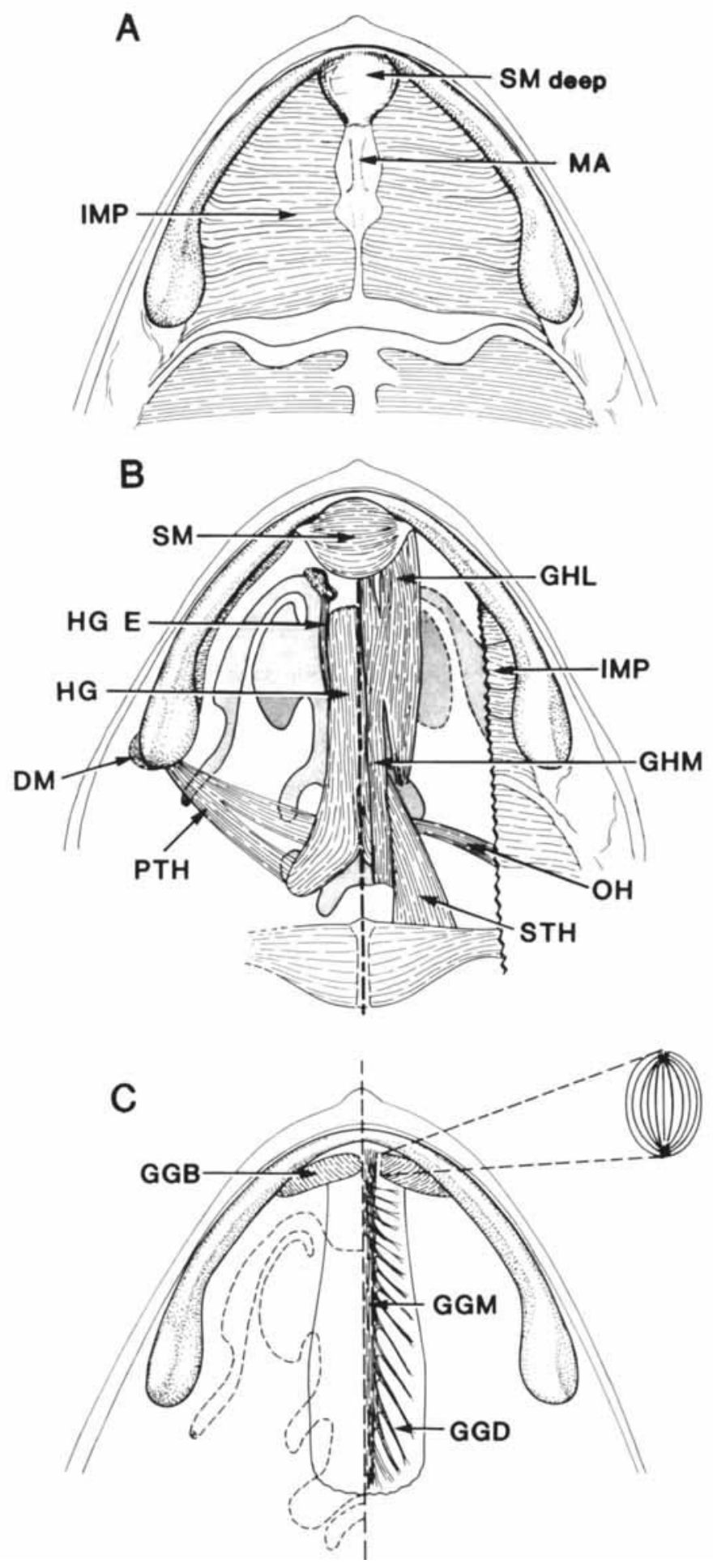
mentalis, all of these and the following muscles are paired.

Dorsal to these longitudinal muscles lie the $\mathrm{Mm}$. genioglossus and hyoglossus, muscles of the tongue proper. In the anterior region, a dense basal mass (M. genioglossus basalis; the "couche inférieure" of Magimel-Pellonier, 1924) forms a thick crescent (or pair of legs) of short, radially arranged fibers that crosses from the bony tip of one mandible to that of the other, posterior to the symphysial region and across the base of the tongue. A second, more dorsal and longer pair of fiber-sets (the M. genioglossus "medialis"; the "couche supérieure" of Magimel-Pellonier, 1924) runs as paired rods along the central, anterior half of the tongue. Its fibers split into bundles that radiate medially and laterally from each rod toward the posterior lingual edge and insert at intervals deep to the mucous membrane of the lingual surface. The $M$. hyoglossus consists of an array of much longer fibers that originates from the posterior horns of the hyoid and passes anteriorly as a rounded bundle ventral to the hyoid plate. The muscle enters the ventral surface of the tongue (adjacent to the thin retrolingual membrane). The body of the $M$. hyoglossus then splits, not into a meshwork of individual fibers, but into discrete defined fascicles that leave the muscle at intervals and run posterolaterally to insert on the dorsal lingual surface, mostly near the middle of the distal surface of the tongue. Where the fascicles traverse the body of the tongue, it appears filled with loose connective tissue, among which pass blood vessels and nerve trunks.

Both sagittal and deep ventral dissections disclose that the proximal portions of the $M$. hyoglossus lie in a tunnel-shaped sinus (Fig. 3 ); this sinus reaches its greatest extent at the

Fig. 1. Bufo marinus. Ventral view of skinned head to show three levels of dissection. (A) Superficial level showing only the M. intermandibularis posterior (IMP) and its connective tissue sheet (MA) covering the M. submentalis (SM deep). (B) Deeper level with the M. intermandibularis posterior reflected and $\mathrm{Mm}$. sternohyoideus (STH) and geniohyoideus lateralis (GHL) and medialis (GHM) removed on the left-hand side. DM, M. depressor mandibulae; HG, M. hyoglossus; HG E, muscular extension of $M$. hyoglossus toward vascular coil; OH, M. omohyoideus; PTH, M. petrohyoideus; SM, submentalis. C. Deepest view with all of these muscles removed and only the $\mathbf{M}$. genioglossus remaining in position. The insert shows the $M$. genioglossus basalis (GGB) in cross-section as an array of short fibers inserting on its two defining raphes. GGD, M. genioglossus distalis; GGM, M. genioglossus medialis.

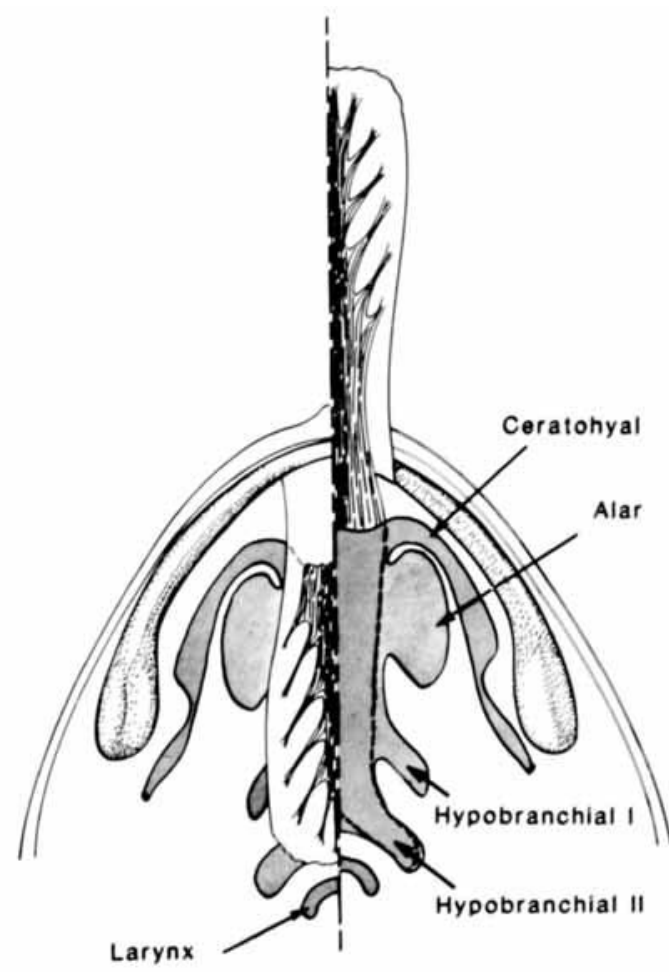

Fig. 2. Bufo marinus. Dorsal view of the dissected lower jaw to show distal portion of the $M$. hyoglossus with the tongue in situ (left) and flipped forward (right side). Note the relative shift of the hyoid plate.

base of the tongue into which it passes anteriorly to terminate in a blind diverticulum. (This arrangement explains Hartog's (1901a) results. Strain of the membranous wall induced by filling the $v$-shaped space should increase the angle between its legs, and pressurization of the contents would tend to straighten it further.) Ventral views show that the membranous walls of the lateral edges of the sinus include the nervous and vascular supplies that follow the sinus into the tongue. The ascending bundles are beautifully looped when the tongue is at rest, suggesting remarkable extensibility that is documented in tongues fixed in the straightened position.

Much of the posterior portion of the hyoid lies dorsal to the pectoral girdle. A thin connective-tissue sheet extends along the ventral surface of the hyoid, between the ceratohyals. Together with the fasciae of the Mm. intermandibularis posterior and geniohyoideus, it forms the ventral and lateral boundaries of the 
A

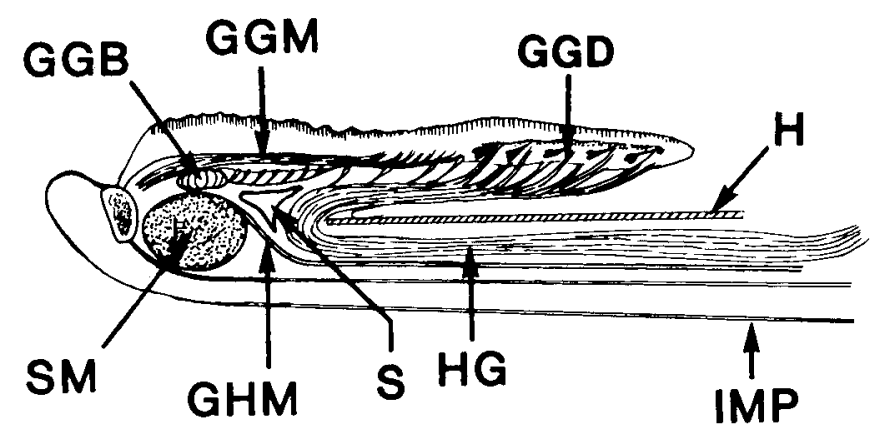

B

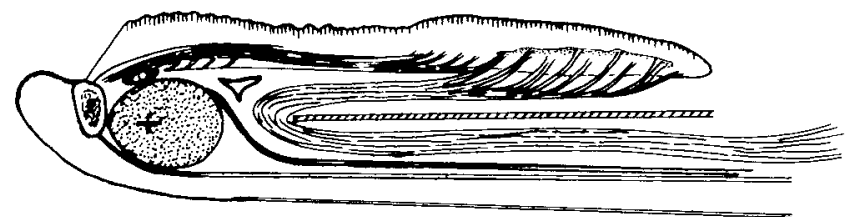

C

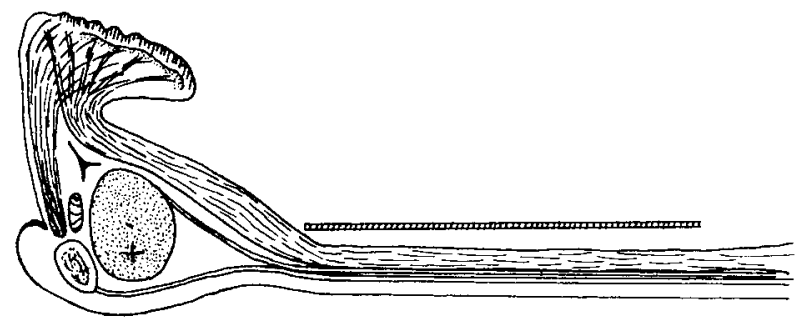

D

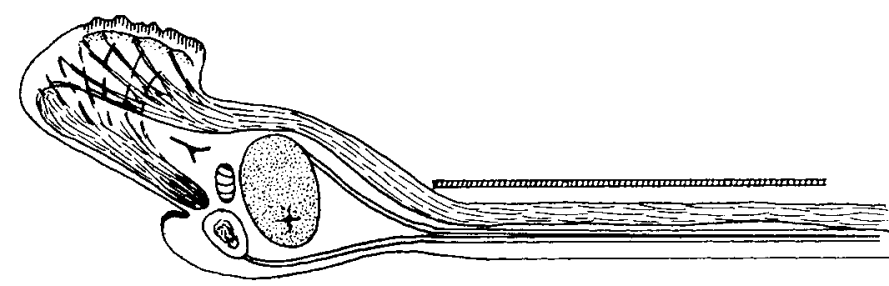

E

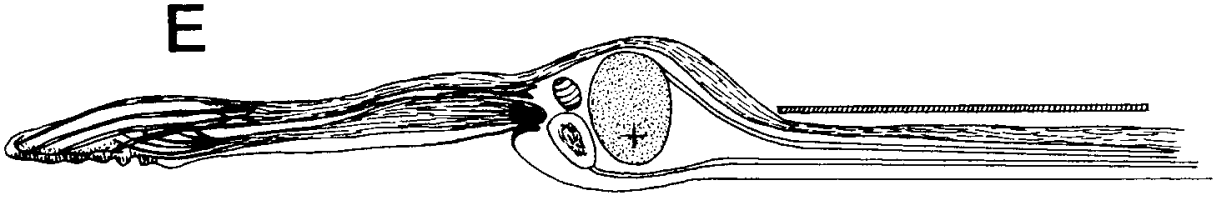


connective-tissue tunnel within which the $\mathrm{M}$. hyoglossus lies. The roof of the tunnel is formed by the body of the hyoid. Both the anterior horns of the hyoid and its processes attach to the reinforced mucous membrane that forms the lateral floor of the oral cavity. Anteriorly, this sheet reflects dorsally along the lateral borders of the $M$. genioglossus and is continuous with the investing fascia of this muscle.

\section{MYOLOGICAL DETAILS \\ M. submentalis (SM)}

The compact, oval, and unpaired M. submentalis (M. intermandibularis anterior) lies at the ventral margin of the anterior tip of the mandible (Figs. 1B and 3). Its fibers are continuous between attachment sites; those of the anterior third curve anteriorly, but most of the fibers lie in an anteriorly concave curve. The M. submentalis is a distinct muscle and not part of the medially separated M. intermandibularis posterior. The anterolateral aspects of the $M$. submentalis are covered with a triangular tendinous sheet that provides attachment for its fibers. This triangular sheet then inserts on the anteromedial tips of the mandibles and the adjacent lateral edge of the mentomeckelian cartilages.

The superficial fibers of the M. submentalis are longer ventrally than dorsally in all re-

Fig. 3. Bufo marinus. Median (A) and sagittal (B) sections through the tongue in situ. (C) Section through the tongue while it is being lifted, with the stiffened rod rotating over the symphysis. (D) Section after the rod has proceeded beyond the symphysis carrying the soft tissues with it. (E) The rod at the end of its travel with the soft tissues being propelled further by their own momentum. Note that the lingual pad has rotated so that it now faces ventrally. Also note the pattern of the radiating fibers of the $\mathrm{Mm}$. geniog. lossus distalis (dashed) and hyoglossus. GGB, M. genioglossus basalis; GGM, M. genioglossus medialis; GHM, M. geniohyoideus medialis; $H$, hyoid plate; $H G, M$. hyoglossus; IMP, $M$. intermandibularis posterior; $S$, lymphatic sinus at base of tongue; SM, M. submentalis.

The diagrams document the mechanism of the propulsion of the tongue. Contraction of the M. submentalis changes the cross-section of this muscle from a horizontal to vertical oval (note cross indicating attachment level) thus increasing its vertical dimension so that the muscle projects above the symphysis. Its movement lifts the stiffened M. genioglossus basalis, and this provides a second wedge transmitting the upward and forward momentum to the side of the rigid $M$. genioglossus medialis. Simultaneously, action of the $\mathrm{Mm}$. geniohyoideus and submentalis depresses the mandibular symphysis and, with this, the anterior fixed tip of the $M$. genioglossus medialis. Thus the anterior tip of this muscle is depressed and its middle is raised and protruded. The resulting couple causes the stiffened medialis to rotate outward carrying along the soft tissues. gions of the muscle (Table 1). The superficial fibers of the posterior region are the longest, those of the middle region are intermediate and those of the anterior part are the shortest. When the M. submentalis is stimulated, the bulk of the muscle is pulled anteriorly against the symphysial region. Simultaneously it shifts dorsally and displaces the overlying tongue.

\section{Mm. intermandibularis posterior and interhyoideus}

The thin, flat M. intermandibularis posterior (IMP) lies in a thin but strong connective-tissue aponeurosis that crosses the gular regions between the ventral edges of the mandibular rami (Fig. 1A). The muscle is paired and its medial aponeurosis is narrow posteriorly, but widens anteriorly where it covers most of the ventral surface of the $M$. submentalis; no muscle fibers cross the midline. Where they approach the mandible, the fibers of the $M$. intermandibularis posterior leave the aponeurosis (which attaches to its ventromedial edge) to turn sharply dorsad and then insert near the dorsomedial edge of the mandible. The fibers of the muscle are arranged in flat bundles that change in their orientation and length from back to front (Table 1). Thus the anterior fibers radiate anterolaterally from the midline, the next group runs nearly straight laterally, and the most posterior fibers pass posterolaterally. A discontinuity marks the transition between the anterior $M$. intermandibularis posterior and the more posterior M. interhyoideus.

The fibers are longest in the posterior region, but gradually decrease in length more anteriorly; the shortest fibers lie near the symphysis. Unilateral stimulation of the fibers moves the central aponeurosis toward the stimulated side.

\section{M. geniohyoideus}

A paired strap-like M. geniohyoideus lies on each side of the midline. Each of these muscles is divided into a wide, short, lateral component (GHL) and a narrower and longer medial portion (GHM) that show some color differences (Fig. 1B). The two portions (which are not truly discrete) are closely attached and appear fused midway along their length; but they separate anteriorly some distance posterior to the position of the M. submentalis, and posteriorly near the level at which the M. sternohyoideus inserts on the hyoid. The superficial fibers of the medial portions of the two sides run 
TABLE 1. Ranges of fiber lengths (in $\mathrm{mm}$ ) of different regions of hyoid and lingual muscles in three Bufo marinus (wts: $693 \mathrm{~g} ; 561 \mathrm{~g} ; 429 \mathrm{~g}$ )

\begin{tabular}{|c|c|c|c|c|}
\hline & \multirow[b]{2}{*}{ Muscle } & \multicolumn{3}{|c|}{ Range of fiber lengths } \\
\hline & & Bufo I & Bufo II & Bufo III \\
\hline \multirow[t]{2}{*}{$\mathbf{M}$} & intermandibularis & $17-20(\mathrm{P})$ & $18-20(\mathrm{P})$ & $17-19(\mathrm{P})$ \\
\hline & posterior & $5-7(\mathrm{~A})$ & $5-8(\mathrm{~A})$ & 4-7 (A) \\
\hline & submentalis & $6-7(\mathrm{P})$ & $7-9(\mathrm{P})$ & $7-10(\mathrm{P})$ \\
\hline & & 4-5 (A) & $4-6(A)$ & $4-6(A)$ \\
\hline & geniohyoideus & $25-27(\mathrm{~L})$ & $26-33(\mathrm{~L})$ & $28-30(\mathrm{~L})$ \\
\hline & & $36-37(\mathrm{M})$ & $38-40(M)$ & $36-39(\mathbf{M})$ \\
\hline & $\begin{array}{l}\text { geniohyoideus }{ }^{1} \\
\text { basalis }\end{array}$ & & $3-5$ & $4-7$ \\
\hline & medialis & & $7-10(\mathrm{~A}$ & $9-11(\mathrm{~A}, \mathrm{~L})$ \\
\hline & & & L) & $13-17(\mathrm{P}, \mathrm{L})$ \\
\hline & & & $13-16(\mathrm{P}, \mathrm{L})$ & $12-19(\mathrm{M})$ \\
\hline & & & $12-17(\mathrm{M})$ & $22-24(\mathrm{C})$ \\
\hline & & & $19-21(\mathrm{C})$ & \\
\hline \multirow[t]{2}{*}{ M. } & hyoglossus & $30-32(\mathrm{~L})$ & $28-37(\mathrm{~L})$ & $28-40(\mathrm{~L})$ \\
\hline & & $50-52(\mathrm{M})$ & $45-52(M)$ & $50-54(M)$ \\
\hline \multirow[t]{4}{*}{ M } & sternohyoideus ${ }^{2}$ & & & \\
\hline & sternal head & & $11-15(D)$ & $10-17(D)$ \\
\hline & & & $19-35(\mathrm{~S})$ & $29-32(\mathrm{~S})$ \\
\hline & abdominal head & & $22-32$ & $23-30$ \\
\hline \multirow{4}{*}{ M. } & omohyoideus $^{2}$ & & $16-17$ & $16-19$ \\
\hline & $\begin{array}{l}\text { petrohyoideus } \\
\text { anterior head }\end{array}$ & & & $12(\mathrm{~A}) ; 17-20(\mathrm{P})$ \\
\hline & middle head & & & 19 \\
\hline & posterior head & & & 13 \\
\hline
\end{tabular}

A, anterior; C, central; D, deep; L, lateral; M, medial; $P$, posterior; S, superficial

1 Because of prolonged nitric acid treatment, the fibers of the $\mathrm{M}$. genioglossus of $B$ ufo $I$ broke on contact and thus entire fibers could not be measured.

2 The $\mathrm{Mm}$. stenohyoideus and omohyoideus of $B$ ufo I were not removed

3 The M. petrohyoideus of $B$ ufo I and $B$ ufo II were not removed.

straight anteroposteriorly from origin to insertion. These fibers form the superficial portion of the medial edge along both the anterior and posterior separations. However, one group of deep fibers crosses from the posteromedial head to join the anterolateral head. These deep fibers form the medial edge of the posterior separation and the lateral edge of the anterior one. Consequently, these are not two separate muscles, but a single muscle with multiple fascicular subdivisions.

The medial portion of the M. geniohyoideus originates from the fascia covering the ventral surface of the laryngeal cartilages. It curves dorsal to the M. submentalis to insert on the dorsomedial surfaces of the mentomeckelian cartilages. The lateral head originates along the posterior horn of the hyoid and passes anteriorly, lateral to the insertion of the $\mathrm{Mm}$. sternohyoideus and omohyoideus. Anteriorly, the lateral heads insert on the ventromedial aspects of the lower jaw; lateral to the mentomeckelian, some of the fibers terminate on the dorsal surface of the $M$. submentalis.

Both the lateral and medial portions of the M. geniohyoideus are parallel-fibered. The deep fibers of the medial head are slightly longer than those of the superficial one, and all medial fibers are longer than the lateral ones (Table 1). Stimulation of the M. geniohyoideus pulls the hyoid anteriorly; when the hyoid is stabilized, action of the muscle deflects the anterior portion of the mandibular arch ventrally.

\section{M. genioglossus}

The paired $M$. genioglossus is extremely complex. It originates from the posterodorsal aspects of the mandibular tips and the mentomeckelians and extends from here into the base and body of the tongue (Figs. 1C, 3). Chemical dissection indicates that the muscle consists of two discrete portions, the basal (GGB) and the medial-distal one (GGM, GGD, Table 1). The former is so deeply tied into connective tissues that Magimel-Pellonier (1924) commented that it could not be dissected intact.

The basal portion (M. genioglossus basalis) consists of two horizontal rods of muscle that curve just dorsal to the $M$. geniohyoideus and posterior to the mandibular symphysis. Each 
rod is rounded and contains thick ventral and dorsal raphes that run parallel to its long axis. The fibers of this basal portion are short, lie at right angles to the length of the rod and attach to both raphes. Cross-sections through the rod show that the anteriormost fibers curve first dorso-anteriorly from the ventral raphe and then dorsoposteriorly to reach the dorsal one; the posteriormost fibers first curve dorsoposteriorly and then dorsoanteriorly toward the dorsal raphe. The more central fibers almost pass in a straight line from one raphe to the other. Each rod is attached laterally to the dorsomedial edge of one mandibular tip and medially to the other rod; however, the entire anterior surface of the arch of the basalis is connected to the skeletal arch.

More dorsally the lingual mass shows a slender medial block of connective tissue, from which arises the long-fibered longitudinal "medialis" portion of the $M$. genioglossus. While the sides of this mass give off fascicles, the main portion of the muscle is organized into a pair of parallel rods that almost reaches the tip of the tongue when this is contracted. The muscle originates as a medial pair of muscular rods from the medial connective tissue raphe at the base of the tongue and from the middorsal edge of the mentomeckelian cartilages. Small fascicles first leave the ventral and lateral sides of this mass just posterior to the basalis portion and run almost at right angles to the medial rod; a horizontal fascial plane separates the dorsally curving posterior fibers of the basalis from these horizontally running fibers of the "medialis." Further sets of fiber bundles then radiate from the lateral and medial aspects of each rod. The many lateral bundles run posterolaterally, and the few medial ones nearly straight posteriorly along the midline; both insert into the lingual surface where they interdigitate between the insertions of the M. hyoglossus. One is tempted to separate this muscular portion into a central "medialis" and a peripheral "distalis." However, the medial and distal sections, while differing in location, represent the two ends of the same fibers, all of which originate from the same raphe of medial connective tissue. Near the tip of the tongue, two large medial bundles of fibers then break up, fanning out posterolaterally, and inserting into the distal pad of the tongue. Even here bilaterality is strictly maintained.

The fibers of the basalis are very much the shortest, and the radiating medial fibers inserting into the distal pad of the tongue the longest ('Table 1). The radiating fibers increase in length proceeding posteriorly from the basalis portion; the straight horizontal fibers of the "medialis" are shorter than the lateral and medial radiating fibers. Stimulation of the basalis portion of the M. genioglossus results in ventroanterior movement that lifts the tongue and rotates its base toward the symphysis. Stimulation of the rod-shaped portion of the medialis constricts this muscle to form a rigid cylinder, while local application of stimuli shifts portions of the tongue.

\section{M. hyoglossus}

The M. hyoglossus (HG) originates as two proximal heads, one from each of the posterior horns of the hyoid (Figs. 1B, 2, and 3). The fibers of the proximal heads follow the course of the posterior horns and merge at the ventroposterior border of the hyoid corpus. Then the muscle passes anteriorly along the ventral surface of the hyoid but (at rest) swings dorsally between its anterior horns to entend posteriorly into the body of the tongue. At this level the muscle starts to break into distinct fascicles; small bundles leave its lateral edges and dorsal surface to insert onto the dorsal surface of the tongue, i.e., adjacent and deep to the lingual pad. The main mass of the muscle continues posteriorly, but a medial separation again becomes obvious. The two distal heads run along the midline on the ventral surface of the tongue just deep to the retrolingual membrane. At intervals, small bundles of fibers radiate from the lateral aspect of each distal head to insert near the periphery of the tongue and along the sides of a poorly defined trough in the mucous membranes that lies on the midline and dorsal to the distal head of the M. hyoglossus. However, the central fiber mass of the distal heads continues to run posteriorly along the midline. Near the lingual tip, each side of the hyoglossus breaks up into discrete fascicles. There is complete overlap of their insertion sites, and both sets of radiating fibers insert in an overlapping pattern across the distal (posterior in situ) tip of the tongue.

The parallel fibers of the $M$. hyoglossus are by far the longest of those in the buccal region (Table 1). The lateralmost fibers are the shortest and the medialmost the longest; there is a gradual increase in fiber length from the lateral to medial portions of each head. Stimulation of the $M$. hyoglossus, when the tongue is extended, produces a localized bulging of the central, lingual surface near the tip and retraction of the tongue toward the mouth. 


\section{M. sternohyoideus}

The M. sternohyoideus (STH) arises medially from the sternum proper and laterally from the external surface of the abdomen. The two heads of origin pass dorsally and anteriorly and join each other dorsal to the coracoid. The muscle then passes between the two heads of the M. geniohyoideus (Fig. 1B). The bulk of the M. sternohyoideus inserts along the lateral boundary of the body of the hyoid; however, an anterior slip of the muscle attaches rostrally on the anterior horn (deep to the GHL in Fig. 1B).

The fibers of both heads of the M. sternohyoideus are arranged in parallel. While the abdominal head is longer than the sternal one, its fibers are divided transversely into an anterior and posterior group by a tendinous inscription that lies just posterior to the origin of the sternal head. The fibers of the anterior part of the abdominal head are generally longer than those of the posterior head. The sternal head shows two longitudinal subdivisions: (1) a ventral group of long fibers that runs medial and parallel to those of the abdominal head and (2) a dorsal group of short fibers that runs anterolaterally deep to the abdominal head. Stimulation of the M. sternohyoideus of one side moves the hyoid posteroventrally and slightly toward that side.

\section{M. petrohyoideus}

The M. petrohyoideus (PTH) originates deep to the M. sternocleidomastoideus (which is deep to the $M$. depressor mandibulae) from the ventral posterolateral portion of the postorbital shelf. The M. petrohyoidei can be divided into one anterior and two posterior portions (Fig. 1B). The anterior portion (M. petrohyoideus anterior) is thin and flat and arises deep to the posterior portions. Its fibers course ventrally and anteromedially to insert on the ventral surface of the body of the hyoid, deep to the $\mathrm{M}$. geniohyoideus and just lateral to the fascial tunnel of the $M$. hyoglossus. The fibers of the more anterior of the two cylindrical posterior heads pass ventroposteriorly and insert on the posterior horn of the hyoid near its posterior process. The fibers of the more posterior head also pass ventral, but more posteriorly than those of the more anterior head, to insert at the tip of the posterior horn at the attachment of the M. hyoglossus.

The fibers of all three heads of the M. petrohyoideus are arranged in parallel. The most ventroanterior fibers of the anterior head are short; however, the fibers of the remaining portion of this head are long and of equivalent lengths. The fibers of the first of the two cylindrical posterior heads are all the same length - but slightly shorter than the long fibers of the anterior head. The fibers of the posteriormost head are also all of the same length but are the shortest of the three heads. Stimulation of the M. petrohyoideus of one side moves the hyoid dorsally and posterolaterally.

\section{M. omohyoideus}

The M. omohyoideus $(\mathrm{OH})$ originates from the dorsal anterior surface of the scapula (Fig. 1B). It inserts on the body of the hyoid just dorsal to the center of insertion of the M. sternohyoideus. Its fibers are parallel, run anteromedially and are of equivalent lengths. Stimulation of the $M$. omohyoideus of one side moves the hyoid posterolaterally.

\section{$M$. depressor mandibulae}

The M. depressor mandibulae (DM) connects the skull to the mandible (Fig. 1B). It originates from the ventral posterolateral portion of the postorbital shelf, passes ventrolaterally and slightly posteriorly over the quadratoarticular joint and then attaches to the posterior edge of the angulosplenial portion of the mandible.

\section{MOVEMENTS \\ General}

The feeding sequence of toads is here subdivided into four phases (1) preparatory, (2) tongue protrusion, (3) tongue retraction, and (4) mouth closing. "Preparatory" starts with forward movement of the toad and terminates just as the mouth starts to open. "Tongue protrusion" involves rotation of the lingual base about the symphysis (rotation phase), followed by elongation of the lingual tip (elongation phase), and ends with impact of the tongue on the prey. "Tongue retraction" ends when the tongue has completed its rotation to the back of the buccal cavity, and "mouth closing" ends as the mandible returns to the closed position (Figs. 4, and 5). It is necessary to record movements of the upper and lower jaws relative to the ground and to each other, and of portions of the tongue relative to the symphysis. Movements of the snout relative to the ground indicate movements of the upper trunk about the forefeet.

The preparatory phase takes $180 \pm 39 \mathrm{msec}$ when the food object is about 2 to $2 \frac{1}{2}$ head lengths from the mandibular symphysis. The 

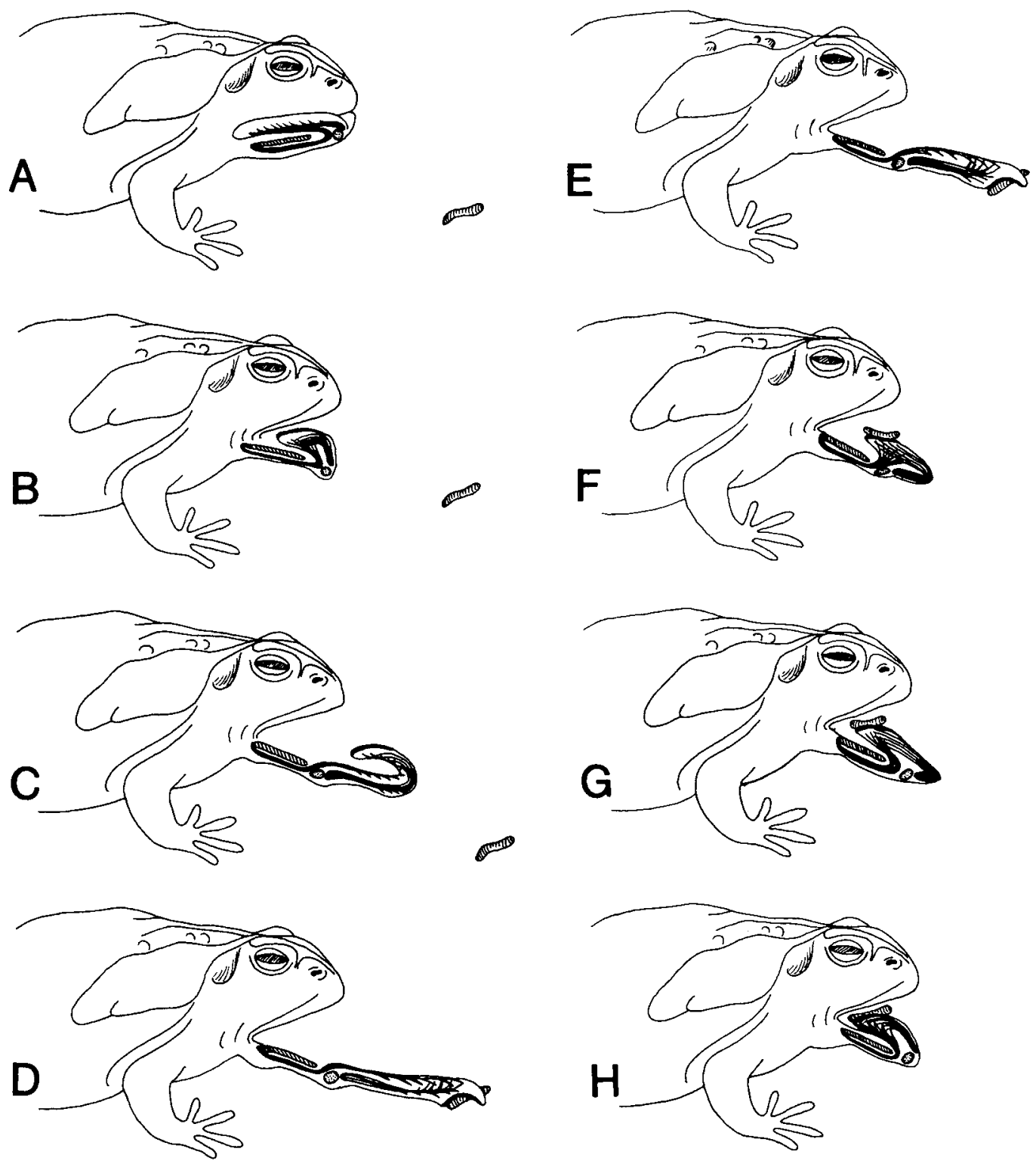

Fig. 4. Bufo marinus. Sketches of toads showing the process of tongue protrusion (left) and retraction (right). (A) Tongue at rest in floor of mouth; (B) the symphysis has been depressed, the Mm. submentalis and genioglossi contracted and the formed rod is rotating carrying the soft tissues along; (C) the rod has rotated beyond the symphysis and the soft tissues are being accelerated; and (D) the mass has been elongated and the soft tissues are impinging on the prey. Note the rotation of the pad (from dorsal to a ventral

position). (E) Tongue starts to retract and prey held by suction-cup effect; (F) the lingual pad has crossed the symphysis and is again depressed while the still formed rod extends beyond it; (G) the pad has moved further into the oral cavity and the rod starts to melt; and $(\mathrm{H})$ the rod has melted completely, M. genioglossi lie posterior to the symphysis, and the mass of the tongue drops ventrally. Note that the pad retracts before the rod. 


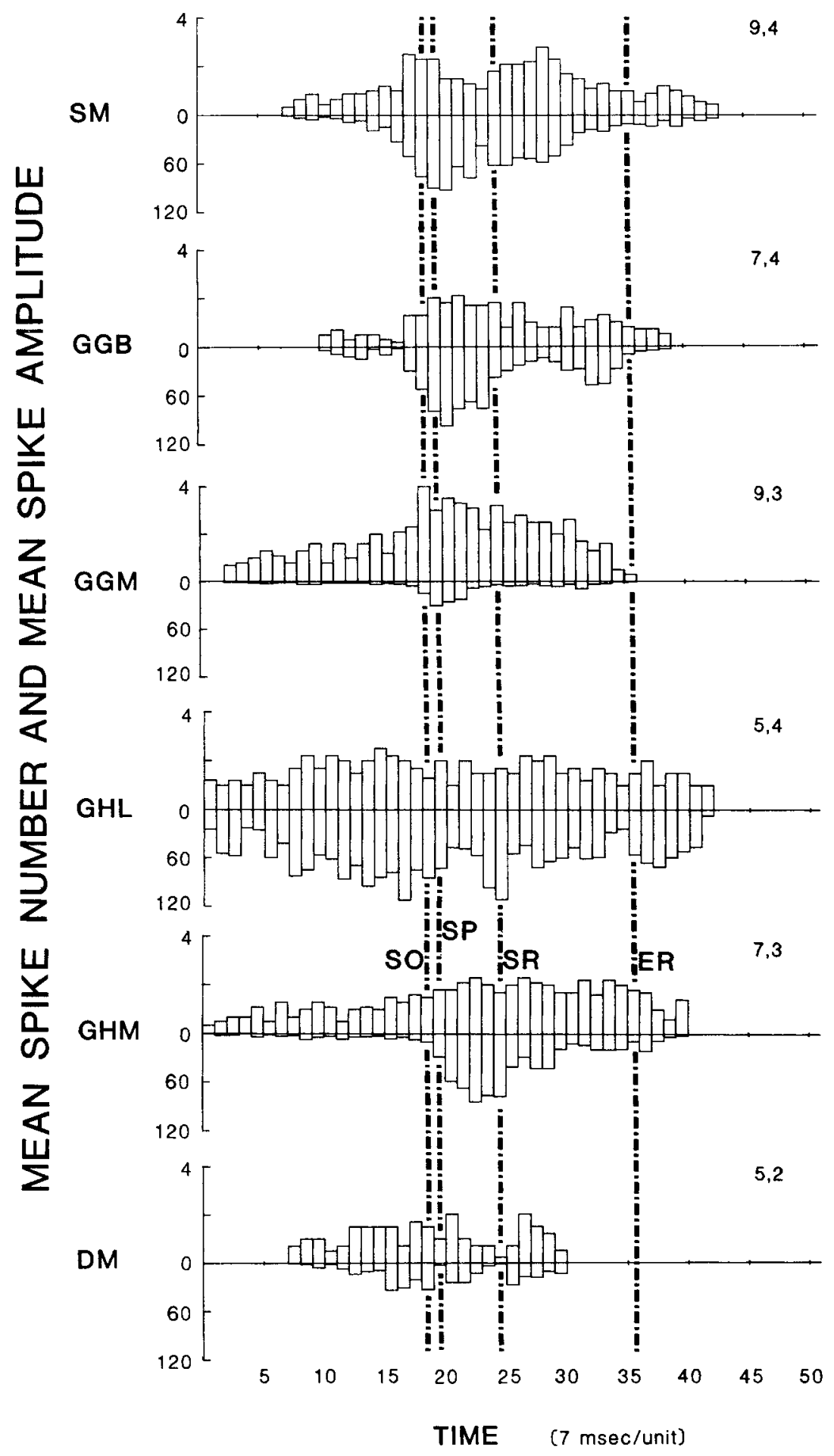


mouth is open for $143 \pm 22$ msec. The initial rapid opening takes only $15.68 \pm 3.17 \mathrm{msec}$. The actual protrusion of the tongue, from the time it lifts from the floor of the mouth until full impact on an object, between 1 to $1 \frac{1 / 2}{2}$ head lengths from the mandibular symphysis, lasts for $36.8 \pm 3.5 \mathrm{msec}$. Closing, which follows after the tongue has returned to the mouth, takes $79.39 \pm 21.65 \mathrm{msec}$.

\section{The preparatory phase}

Movements of the prey provide the primary cues for the initiation of the preparatory phase (Ingle, 1976; Ewert et al., 1970), although members of some populations of Bufo marinus apparently feed on vegetation (Zug and Zug, 1979) and individuals have been noted to take dog and cat food (Alexander, 1964; Clark, 1974). Our toads ignored all dead prey and tended to make preliminary visual discrimination among prey items. When living prey stops moving, the toad stops its approach until the prey again starts to move. Toads have definite control of the direction and distance of the flip. Direction is mainly indicated by positioning the head toward the prey. However, there is some lateral control, as indicated by toads that tilted their head prior to flips; and a specimen that was blind in one eye always flipped the tongue asymmetrically.

When prey is introduced some distance away, a hungry toad assumes an alert position. The forelimbs are then extended, raising the head and upper trunk, the snout is pointed toward the prey, the eyes are open, and the head is motionless. The toad may walk or hop toward prey in intermittent movements; the oscillation cycles of the buccal floor continue.

Fig. 5. Bufo marinus. Summary diagram to show EMGs of some buccal muscles during the flip of the tongue. Numbers on right side give the number of flips, followed by the number of animals. Each bar of the graph shows the mean spike number (above the line) and the mean spike amplitude in units of .08 millivolts each (below the line). The dashed lines define the intervals of preparatory, protrusive, retractive, and closing movements by defining the start of opening (SO), start of tongue protrusion (SP), start of retraction (SR) and end of retraction (ER). The sequences are aligned on the start of opening.

The muscles in order are the Mm. submentalis (SM), genioglossus basalis (GGB), genioglossus medialis (GGM), geniohyoideus lateralis (GHL), geniohyoideus medialis (GHM), and depressor mandibulae (DM). Note the differing relationships between mean spike number and amplitude during the phases of the tongue flip.
If the prey is dropped immediately in front of the snout there may be no discernable further preparation except that the eyes are always covered by the nictitating membrane prior to the flip. The tongue is then flipped without further movement of the head or trunk. Occasionally the snout is depressed slightly prior to the flip of the tongue, which then includes mainly the rotation but little extension. If prey is placed more than one, but less than two, head lengths from the snout, the preparatory phase continues by extension of the hindlimbs. This rotates the upper trunk over the extended forelimbs, so that the snout and anterior trunk are moved forward and then downward toward the prey at a constant rate. Simultaneously, movements of the buccal floor cease, and the nictitating membrane starts to cover the eye signalling protrusion.

\section{The tongue protrusion phase}

Protrusion involves tightening of the lingual mass near the mandibular symphysis, opening of the mouth, rotating a stiffened lingual core away from the buccal floor and around the symphysis, shifting of the lingual soft tissues on the head of the core past the symphysis, their sliding along the core and impacting onto the prey (Fig. 4). The thickened, dimpled posterior lingual pad impacts onto the prey; while the pad faces dorsad at rest, it faces ventrad as it impacts onto the prey. The protrusion starts as the mouth is opening, and the moving tongue never touches the upper jaw. The force of impact imparts pressure on the intrinsic lingual glands, and some of their secretion is emptied onto the contacted surface.

Movements of the tongue appear to precede opening of the mouth as the first film frames always show the lingual tissues bunched near the symphysis. The next event appears to depend upon the angle at which the tongue has to be projected. If the prey is some distance away and the projection angle is close to horizontal, projection starts immediately. Indeed it may proceed with the mouth only partially opened so that the rolling tongue barely clears the roof of the mouth. If the prey is closer to the snout, the mandible first drops through $20^{\circ}$ to $30^{\circ}$ before the tongue is activated.

The first stage of the flip is seen as a strong ventral deflection of the entire anterior quarter of the lower jaw; this forms an initial sharp bend in the floor of the mouth. This bend is apparently permitted by rotation of the anterior ossified zone of the mandible about the posterior one at the unfused mid-mandibular 
articulation. Simultaneously the base of the tongue appears to rise from the floor of the mouth, rotating anteriorly. In frontal view, the protruding mass appears wedge-shaped; the outward rotation forms the tongue into a narrow leading edge as it crosses the level of the symphysis. This edge extends the full height of the tongue during passage over the symphysis and during the first stage of rotation beyond the mouth. Lateral views show that the soft tissues, which at rest occupy the dorsal lingual surface, are trailing and that much of the soft tissue still remains within the mouth. As the lower jaw drops further, the initial bend of the symphysial portion becomes less acute relative to the posterior portion of the lower jaw, as if this had caught up to the depressed mandibular tips.

Within another $20 \mathrm{msec}$ the ridge has continued over the symphysis. By less than 30 msec the basal portion has achieved its final position; it then extends beyond the symphysis along a more or less straight line toward the prey. During the last stages of straightening, the soft tissues have begun to follow the rotating base; and the tongue looks heart-shaped in frontal view. The anterior movement of these tissues continues along the axis formed by the basal muscles. The now anteriorly extended basal portion remains fixed, and the more dorsal part slides across the symphysis and continues to slip along the basal mass that points toward the prey. The separation between the anteriorly moving soft tissues and the stationary basal portion reflects the angle between the extended tongue and the ground.

The lower jaw generally continues to accelerate downward until the basal portion points at the prey; in most flips the jaw reaches maximal opening acceleration at about $25^{\circ}$ of gape. Sometimes this movement involves the entire head. The soft tissues of the lingual tip lag 7 msec behind the base; they travel anteriorly for $21 \mathrm{msec}$ after they pass the tip of the mandible. At the end of the protrusion phase, the mouth gapes about $60^{\circ}$.

Whatever the distance between head and prey, the lingual tip unrolls onto the surface; but it stretches much more when the prey object is a head width or farther from the symphysis. The inertia inherent in the moving mass can be seen to deform it around any irregularities of the substratum.

\section{The tongue retraction phase}

The mouth is open throughout the retraction phase, and the snout may move upward and posteriorly (Fig. 4). Lingual retraction appears to begin even before or within $10 \mathrm{msec}$ of impact of tongue onto the ground and prey. (Several times, retraction was apparently triggered too early, the soft tissues were arrested during the outward rotation, and their extension reversed before they hit the surface. The soft tissues first swung posteriorly and downward but then reversed direction, swinging anteriorly and upward to lie dorsal to the lingual base.)

The extensible nature of the soft lingual tissues and the mucous membranes is the most striking aspect of the retraction phase. The papillate surface of the tongue (Waller, 1849) generally seems to be pulled out of contact with the ground by a pull on the medial aspects of the lingual surface. Anterior views of the tongue show a deep depression of the medial surface during retraction. This deformation apparently induces a suction effect on larger prey, as noted by a film record in which the tongue was seen to adhere to a petri dish and lift it off the substrate, the bond only being broken when the dish hit the snout. The soft tissues connecting the pad-like lingual tips to the lingual base, as well as the mucous membranes connecting lingual tip to symphysis, appear to be remarkably extensile. The lingual pad and its attached prey will have proceeded far into the buccal cavity before the basal rod and the connective tissues of the lingual base will have completed crossing the symphysis. The basal muscle mass, which has remained fairly rigid during the start of retraction, does not remain erect thereafter and rotate backward across the symphysis; rather, it appears to melt over the symphysial region.

Consequently, movements show hysteresis between the flip and the return. During the flip the surface of the tongue moves almost twice as fast as during the return. The basal rod moves out first accelerating in straight rotation over the symphysis. The lingual pad on the distal tip moves out last. Once the soft tissues have passed the symphysis, they unroll at a regular and relatively constant rate; their velocity never reaches that of the initial rotation of the base. In contrast, the lingual pad returns most rapidly, while the basal rod follows at less than half of its velocity first rotating and then deforming around the symphysis.

As the soft tissues pass the mentomeckelian region, the edge of the jaw again rotates ventrally, forming a prominent V-shaped notch at the symphysis. The tip of the tongue first moves directly posteriorly for 14-21 $\mathrm{msec}$, 


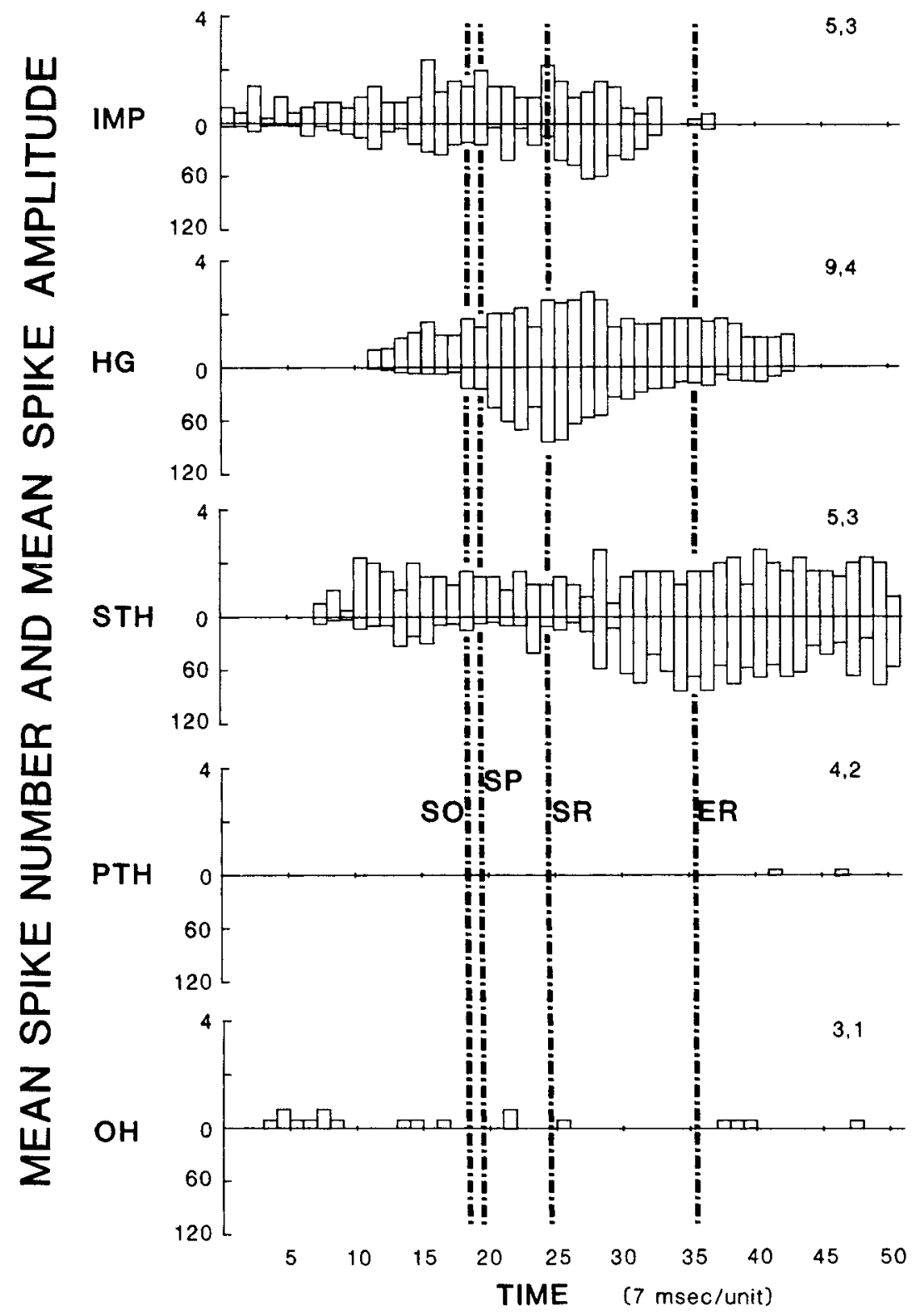

Fig. 6. Bufo marinus. Summary diagram to show EMGs of some buccal muscles during the flip of the tongue. Numbers on right side give the number of flips, followed by the number of animals. Each bar of the graph shows the mean spike number (above the line) and the mean spike amplitude in units of .08 millivolts each (below the line). The dashed lines define the intervals of preparatory, protrusive, retractive, and closing movements by defining the start of opening
(SO), start of tongue protrusion (SP), start of retraction (SR) and end of retraction (ER). The sequences are aligned on the start of opening.

The muscles in order are the $\mathrm{Mm}$. intermandibularis posterior (IMP), hyoglossus (HG), sternohyoideus (STH), petrohyoideus (PTH), and omohyoideus $(\mathrm{OH})$. Note the differing relationships between mean spike number and amplitude during the phases of the tongue flip. 
bunching onto the lingual base. The entire tongue starts to curl upward and posteriorly about $7 \mathrm{msec}$ later. The tip of the tongue reaches maximal backward acceleration as it approaches the symphysis about $35-42$ msec into the retraction phase. By then, the mouth has opened $10^{\circ}$ more than during the protrusion phase, and backward acceleration at the tip of the tongue decreases. At the end of retraction, the base and tip of the tongue drop ventrally.

Maximal protrusive acceleration of the lingual tip is twice the magnitude of retraction (when holding a prey object of $0.2 \mathrm{~g}$ mass).

\section{The mouth closing phase}

The mouth begins to close after the surface of the tongue has returned to a horizontal position near the back of the oral cavity. If the animal rotated its trunk over the forelimbs, the head and body will still continue to rotate backward and upward throughout closing. Maximal closing acceleration of the mandibles occurs within 14 msec after the start of closing and decreases thereafter. In frontal view, the $\mathrm{V}$-shaped ventral bend of the mentomeckelian region disappears suddenly, after the entire mass of the tongue has returned to its horizontal position and the mandibles then are again parallel to that of the upper jaw. The oscillatory movements of the buccal floor begin again once the mouth closing phase is complete.

\section{ELECTROMYOGRAPHY}

\section{General}

Electromyograms (EMGs) coincident with the flip and retraction of the tongue are described for the lingual, hyoid and mandibular muscles (Figs. 6-8). These test whether the muscles in question are actually active at particular periods and whether the individual actions, observed during stimulation, indeed occur coincident with the movements recorded on film. Activity may be almost continuous while the tongue is flipped and returned to the mouth. Consequently, the onset and cessation of muscular activity by themselves provide inadequate iniormation about muscular activity during prey capture. However, several descriptions of the EMG differ markedly among the subdivisions of the movement sequence; quantification of the EMGs simplifies interphase comparisons.

The EMG for each major muscle was determined during at least five tongue flips coincident with cine; further intermuscle comparisons were also made. EMG amplitude, spike number, and the product thereof were then graphed for each movement sequence. The spike amplitude and product gave the best correlations with mechanical events; indeed, for certain muscles the spike number by itself was remarkably uninformative, as it remained relatively constant even though EMG amplitude changed markedly (Fig. 6). The product is referred to below, unless specific mention is made of an alternate comparison (Fig. 7). The level of activity during each subdivision is given as a percentage of the maximum value of the product shown during a movement sequence. (See Figs. 7 and 8 for absolute values).

Comparisons among many toads indicate that the standard errors of the product of spike number and amplitude determined from EMGs of, for instance, the M. submentalis and $M$. geniohyoideus medialis are relatively low for the protrusion phase and show excellent agreement from flip to flip (Fig. 9). In contrast, the firing patterns (and numerical values) of these muscles differ markedly during the preparatory phase, during tongue retraction and during closing of the mouth.

\section{The preparatory phase}

During most of the preparatory phase, while the upper trunk rotates toward the prey, activity levels of the $\mathrm{Mm}$. genioglossus basalis and medialis, intermandibularis posterior, depressor mandibulae and submentalis are low and variable; whereas that of the $M$. geniohyoideus lateralis is high.

The activity level of the M. genioglossus basalis fluctuates between 0 and $40 \%$, that of the M. genioglossus medialis between 0 and $10 \%$, that of the M. intermandibularis posterior between 5 and $85 \%$, that of the M. depressor mandibulae between 10 to $100 \%$ and that of the $M$. submentalis between 0 to $60 \%$. However, the $M$. geniohyoideus lateralis, is very active, generally reaching between 60 and $100 \%$. The Mm. geniohyoideus medialis, hyoglossus, and sternohyoideus may show occa-

Fig. 7. Bufo marinus. Summary diagram to show EMGs of the same buccal muscles and flips shown in Figure 5 . Each bar of the graph shows the mean spike number times mean amplitude as a percentage of the maximum value; the maximum value of cumulative voltage in units of $.08 \mathrm{mil}$ livolt is given for each graph. Note that these cumulative values correlate better with the phases of the lingual flip than does either the mean spike number or mean amplitude separately. 


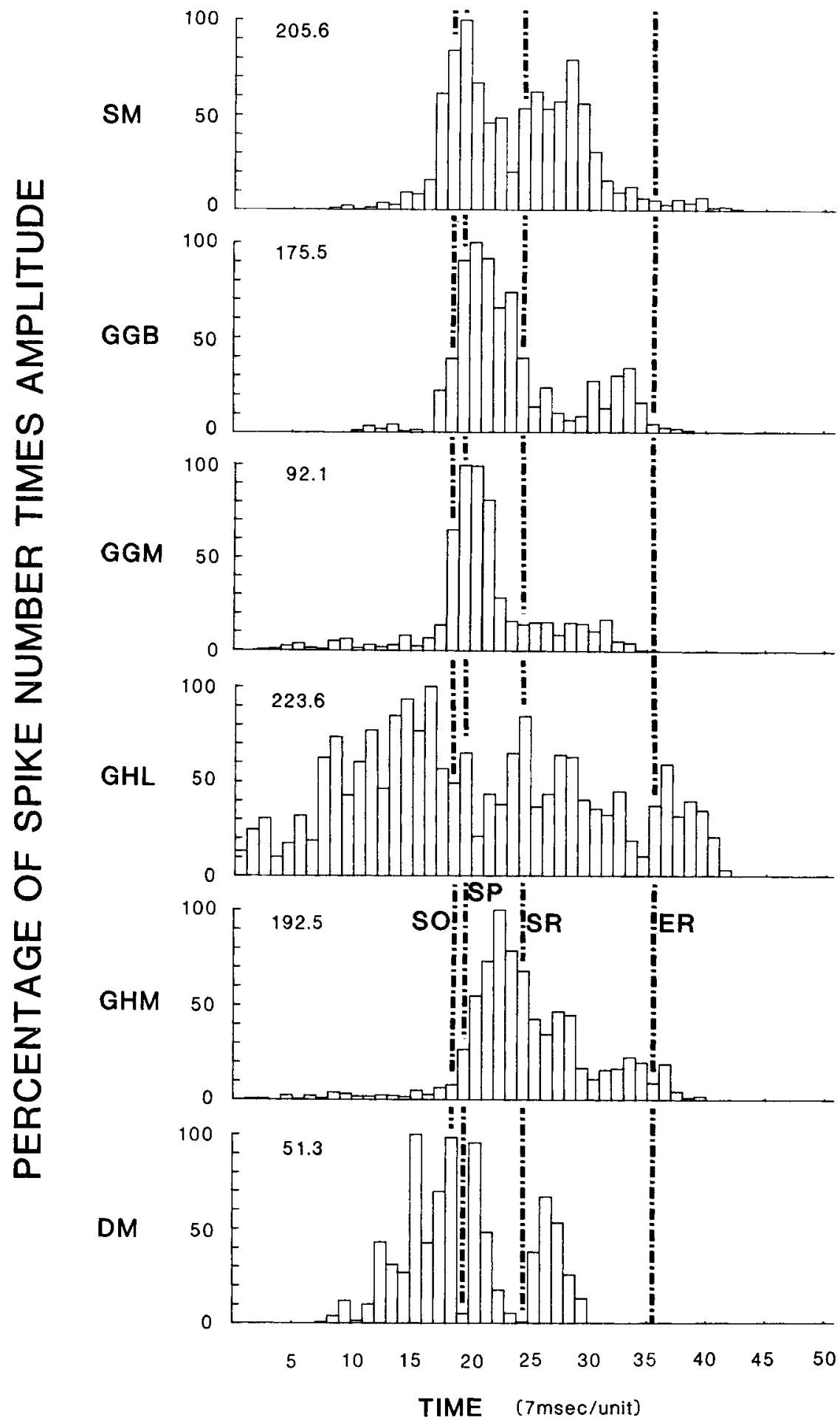




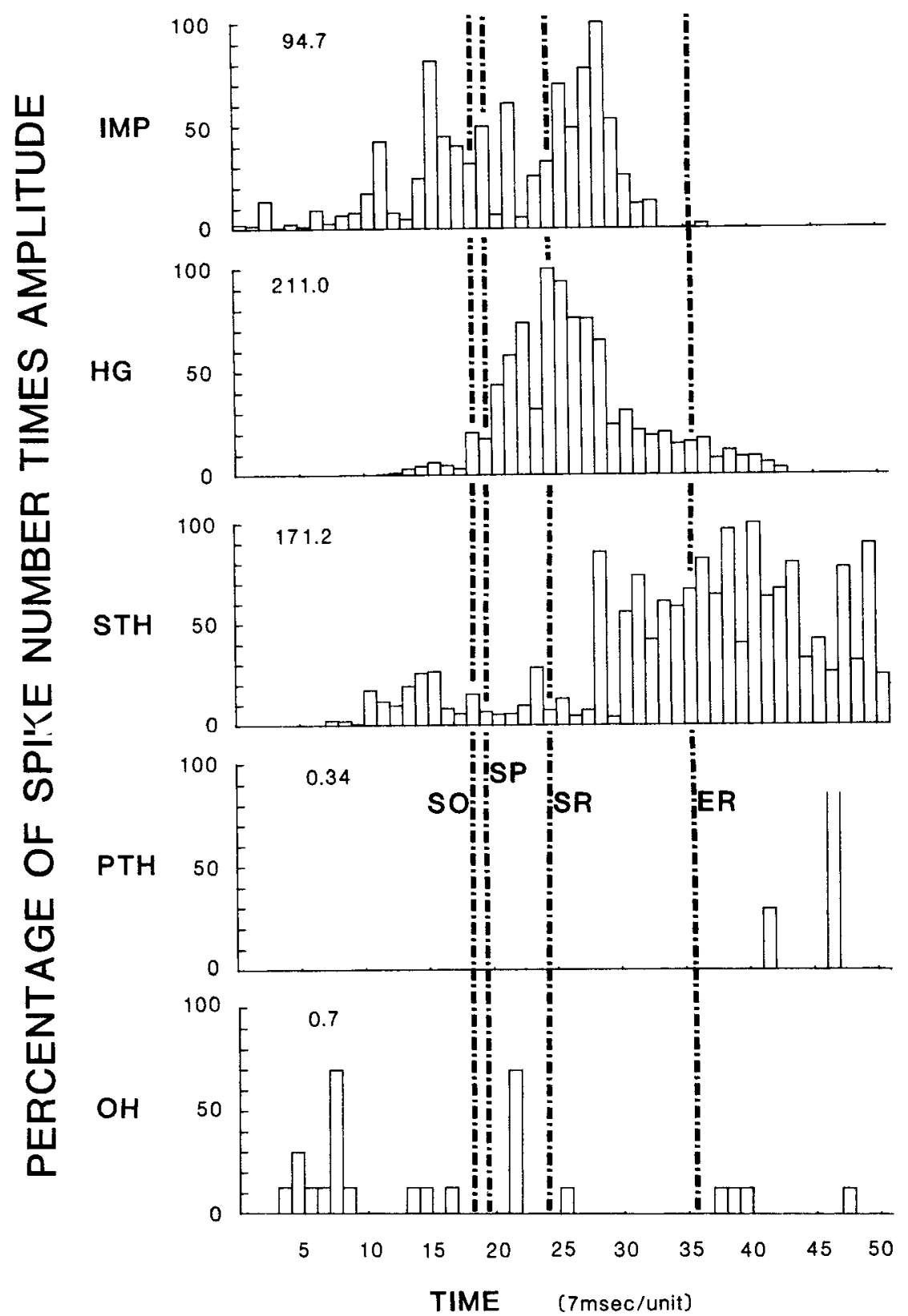

Fig. 8. Bufo marinus. Summary diagram to show EMGs than do either spike number or mean amplitude separately. of the same buccal muscles and flips shown in Figure 6 . Each bar of the graph shows the mean spike number and mean amplitude as a percentage of the maximum value; the maximum value of cumulative voltage in units of $.08 \mathrm{mil}$ livolt is given for each graph. Note that these cumulative values correlate better with the phases of the lingual fip

The diagram shows clearly that the $M$. sternohyoideus shows only minor activity until retraction. The relative values for the $\mathrm{Mm}$. petrohyoideus and omohyoideus are even more misleading as seen by the maximum values given for each graph. However, neither of these muscles makes any significant contribution to protrusion or retraction. 


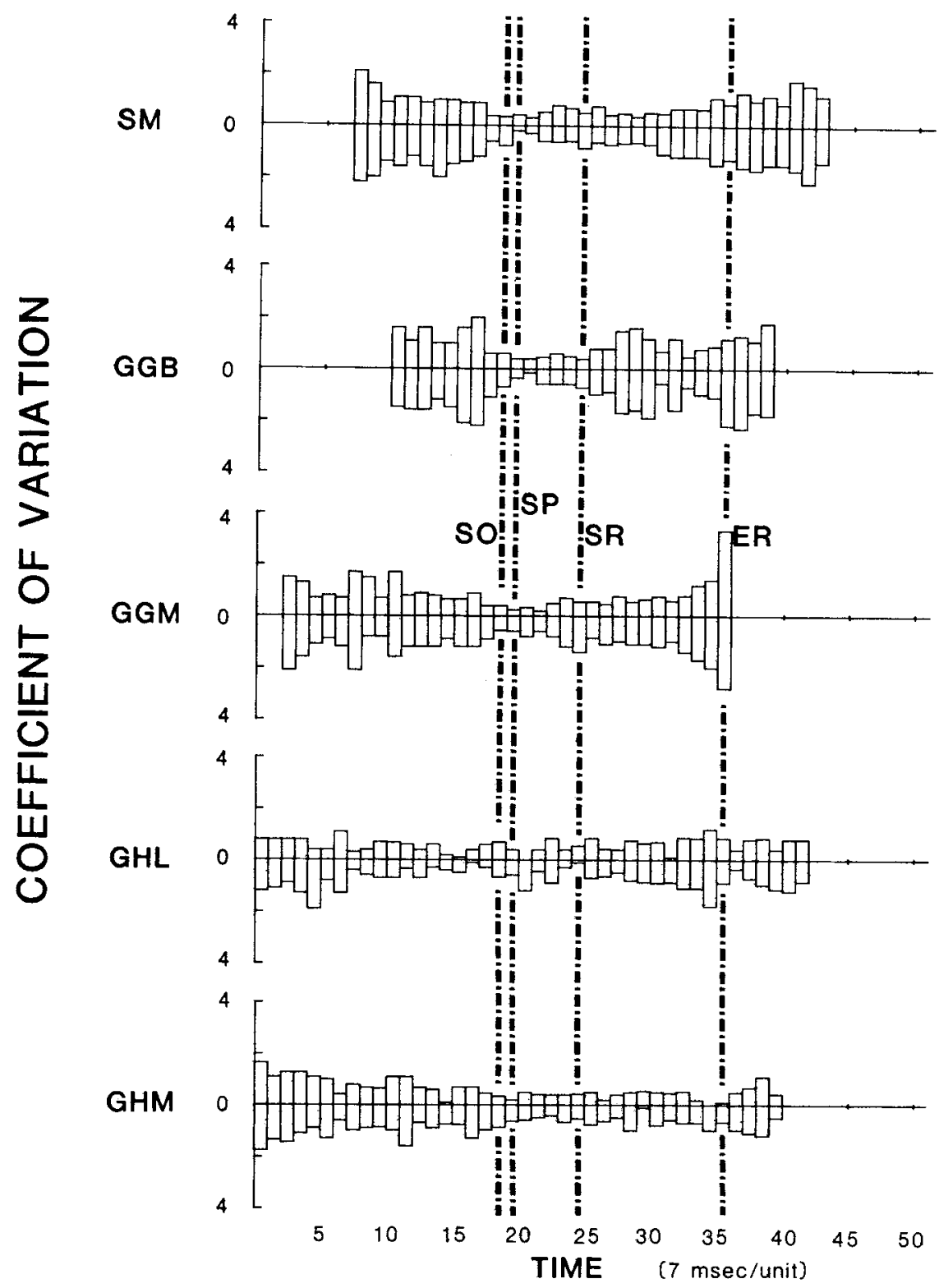

Fig. 9. Bufo marinus. Coefficients of variation for spike number (above line) and amplitude (below line) of the EMGs for each of the intervals of a lingual flip. The values are for the same flip sequences and muscles as shown in Figure 5.

Note that variability for the muscles involved in the flip appears to be least during protrusion and greater during retraction, closing, and preparation. 
sional bursts of low-level activity (generally below $20 \%$ ). The M. petrohyoideus anterior is silent, whereas the M. omohyoideus shows intermittent low-level bursts of activity.

\section{The protrusive phase}

With the exception of the $\mathrm{Mm}$. petrohyoideus anterior, all the muscles from which we recorded are active during protrusion. However, the level of activity changes from the start of protrusion, when the basal rod of the tongue forms and rotates over the symphysis, to its end when the inertia of the soft tissues of the tongue stretches them toward the prey.

The $\mathrm{Mm}$. submentalis, genioglossus basalis and medialis, and geniohyoideus lateralis, all show high levels of activity as the base of the tongue is stiffened and the tips of the lower jaw are depressed. Activity of the M. submentalis increases to a level of 80 to $100 \%$, that of the $\mathrm{M}$. genioglossus basalis increases to 80 to $100 \%$, that of the M. genioglossus medialis increases to 50 to $100 \%$, and that of the M. geniohyoideus lateralis decreases to 50 to $70 \%$. Simultaneously, activity of the M. geniohyoideus medialis increases to 50 to $60 \%$, that of the $\mathrm{M}$. depressor mandibulae is between 90 and $100 \%$, and that of the M. intermandibularis posterior varies between 15 and $50 \%$. Activity of the M. sternohyoideus remains below a $20 \%$ level, the $M$. omohyoideus may show an occasional burst of low-level activity, while that of the M. hyoglossus increases slightly to 0 to $30 \%$.

As the stiff basal rod of the tongue rotates about the depressed symphysis, the $\mathbf{M}$. genioglossus basalis and medialis, as well as both the $\mathrm{Mm}$. geniohyoideus lateralis and medialis, show high levels of activity; whereas the activity of the $M$. submentalis decreases. The $\mathrm{Mm}$. genioglossus basalis and genioglossus medialis, continue to fire at levels of 80 to $100 \%$ and 50 to $100 \%$, respectively. Activity of the M. geniohyoideus medialis increases to 70 to $80 \%$; while that of the $M$. submentalis decreases to $50 \%$ where it remains steady, and that of the $M$. geniohyoideus lateralis decreases to below $50 \%$. Activity of the M. sternohyoideus remains below $20 \%$, while that of the $M$. hyoglossus increases slightly to a level of 30 to $40 \%$.

As the basal lingual rod has rotated into a position parallel to the lower jaws and the soft tissues are thrown toward the prey, activities of the Mm. submentalis, genioglossus basalis, and genioglossus medialis change. As the lingual tip passes the symphysis, the activity of the M. submentalis drops to below $40 \%$, but again increases to 60 to $70 \%$ as the lingual tip reaches the prey. Activity of the M. genioglossus basalis initially decreases to below $70 \%$; it varies considerably thereafter, either increasing to 75 and $100 \%$ or remaining near $50 \%$. Activity of the $M$. genioglossus medialis also varies considerably between 0 and $50 \%$. Activity of the M. geniohyoideus lateralis is between 40 to $70 \%$ as the lingual tip passes from the mouth and reaches the prey, whereas activity of the $M$. geniohyoideus medialis increases to 75 to $100 \%$. Simultaneously, activity of the M. hyoglossus first rises to between 50 and $75 \%$ but then decreases to below $40 \%$ as the lingual tip reaches the prey. The $M$. intermandibularis still shows marked variability ranging between 5 and $60 \%$; however, its activity generally ranges between 25 and $35 \%$ as the tip reaches the prey. Activity of the $M$. depressor mandibulae shows a level between 10 and $50 \%$. The $M$. sternohyoideus remains active below $30 \%$, and the $M$. petrohyoideus anterior is silent.

During the protrusive phase, the mean numbers of spikes generally correlate positively with the mean spike amplitudes for the $\mathrm{Mm}$. submentalis, genioglossus basalis, geniohyoideus medialis and hyoglossus (Fig. 6). However, for the $\mathrm{Mm}$. geniohyoideus lateralis, depressor mandibulae, sternohyoideus, and intermandibularis posterior, changes in the mean spike number show no obvious correlation with mean spike amplitude.

\section{The retraction phase}

All muscles, except the M. petrohyoideus anterior, are active during the retraction phase. However, their activity levels differ considerably.

During the initial retraction of the soft tissues of the tongue, muscular activity of the $M$. hyoglossus increases to 90 to $100 \%$, and the $M$. genioglossus medialis fires at a level between 20 and $50 \%$. As the soft tissue mass folds on itself and moves toward the mouth, the M. submentalis is active between 50 and $75 \%$, the $M$. genioglossus basalis between 20 and $40 \%, M$. genioglossus medialis below $20 \%$, and the $M$. hyoglossus between 50 and $75 \%$. Activity of the $M$. geniohyoideus lateralis increases to $70 \%$ and to $80 \%$, but then decreases to below $60 \%$. Activity of the M. geniohyoideus medialis first drops below $70 \%$ as the tongue begins to fold; it then drops below $50 \%$ as the lingual tip approaches the symphysis. As the mouth opens further, the activity of the M. depressor man- 


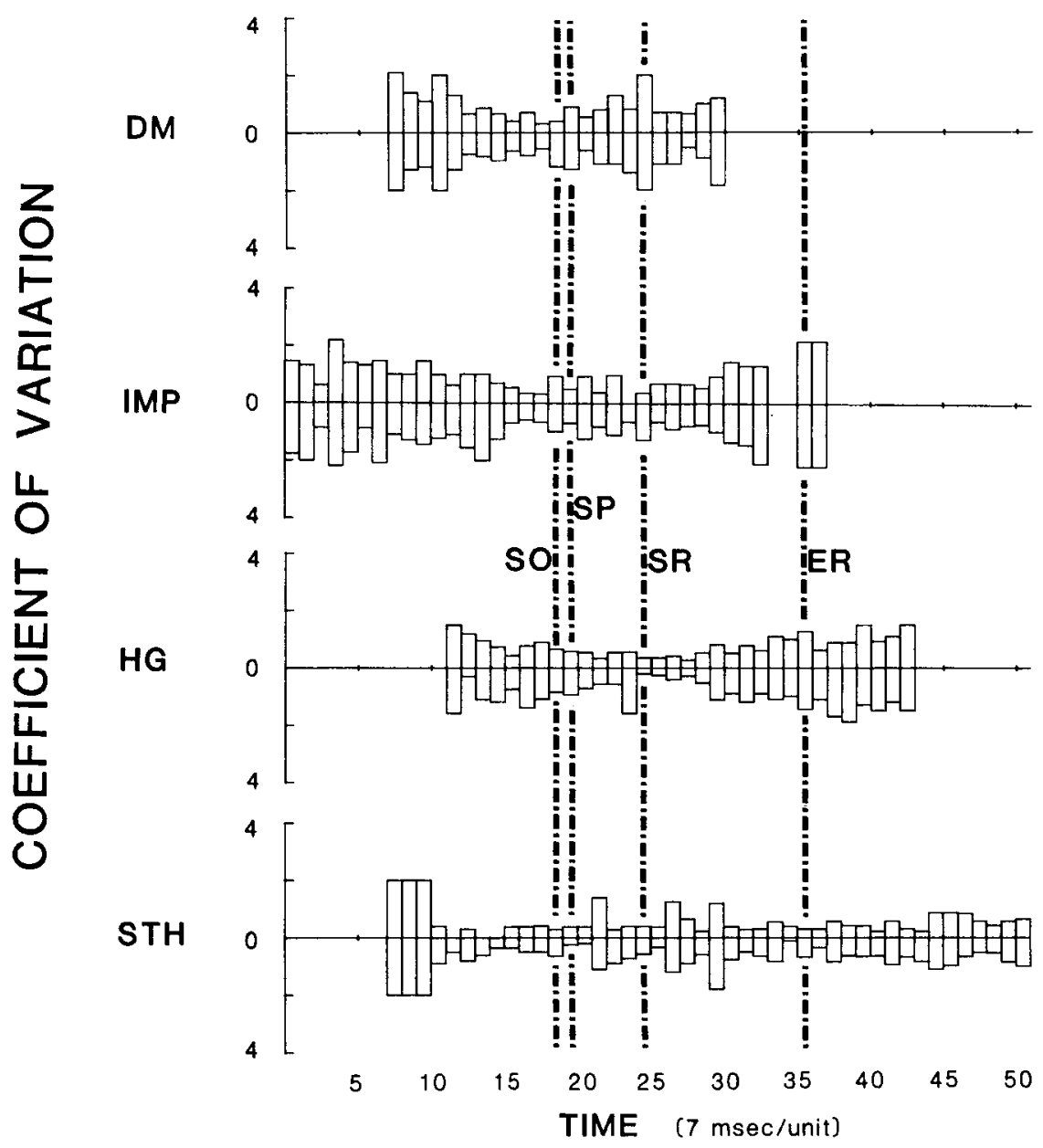

Fig. 10. Bufo marinus. Coefficients of variation for spike number (above line) and amplitude (below line) of the EMGs for each of the intervals of a lingual flip. The values are for the flip sequences and muscles as shown in Figure 6, though

the $\mathrm{Mm}$. petrohyoideus and omohyoideus have been omitted. Note that variability for the $M$. hyoglossus appears to be least during retraction.

dibulae first increases to $70 \%$ but then drops to below $40 \%$. Activity of the M. intermandibularis posterior increases to 75 to $100 \%$, as the pad approaches the symphysis, but then drops to below $60 \%$ as the pad enters the buccal cavity. Activity of the M. sternohyoideus first remains below $30 \%$, but then increases to $50 \%$ to $90 \%$ when the pad crosses the symphysis.

As the soft tissues of the tongue are retracted over the symphysis, activity of the Mm. submentalis, genioglossus basalis, intermandibularis posterior, and geniohyoideus medialis decreases to levels below $40 \%$; it remains below
$40 \%$ as the retrusion phase ends and the lingual pad reaches the back of the oral cavity. The M. genioglossus medialis shows occasional bursts of low-level activity below $10 \%$. The $M$. depressor mandibulae becomes silent before the tongue reaches the back of the oral cavity. Whereas the $\mathrm{Mm}$. geniohyoideus lateralis, hyoglossus, and sternohyoideus are active into the closing phase, the $M$. petrohyoideus anterior is silent. Activity of the $M$. geniohyoideus lateralis varies markedly as the lingual mass folds posteriorly past the symphysis to reach the back of the oral cavity, showing bursts of 
activity ranging from 10 to $50 \%$. Activity of the M. hyoglossus is 60 to $80 \%$ as the tip passes the symphysis but then decreases to below $40 \%$ as the retraction phase ends. Activity of the M. sternohyoideus is at 60 to $70 \%$ as the lingual tip passes the symphysis and remains active at this level to the end of the retraction phase.

During the retraction phase, changes in the mean number of spikes again generally show a positive correlation with mean spike amplitude of the $\mathrm{Mm}$. submentalis, genioglossus basalis, and hyoglossus. The mean number of spikes of the Mm. geniohyoideus medialis and lateralis, sternohyoideus, and intermandibularis posterior remain relatively constant; whereas their mean spike amplitudes changes. In general, the mean amplitudes of these latter muscles are more informative than their mean spike numbers; however, the product of the means is most informative. The standard errors of the $\mathrm{M}$. hyoglossus are lowest during retraction (Fig. 10).

\section{The closing phase}

During closing of the mouth, the Mm. depressor mandibulae, geniohyoideus medialis, and intermandibularis posterior are silent. The $\mathrm{Mm}$. submentalis, genioglossus basalis, genioglossus medialis, geniohyoideus lateralis, and hyoglossus show bursts of activity, the levels of which vary considerably but are below $40 \%$. However, activity of the $M$. sternohyoideus increases to 75 to $100 \%$ during the first half of closing and then becomes highly variable. The $\mathbf{M}$. petrohyoideus anterior is silent throughout most of the closing phase, but the $M$. omohyoideus may show an occasional burst of low-level activity. However, these muscles are active at the very end of closing and during the subsequent buccal oscillations. In addition, the $\mathrm{Mm}$. geniohyoideus medialis and lateralis, intermandibularis posterior and submentalis show low levels of activity coincident with the buccal oscillations; however, the $\mathrm{Mm}$. genioglossus basalis and medialis are then silent. This differential activity also provides an indicator of whether electrodes lie within the genioglossal muscles or in muscles ventral to them.

\section{DISCUSSION \\ Meaning of the EMG}

Almost all of the buccal muscles fire at different levels during each of the activity periods. Consequently, the relative magnitude of activity rather than its onset and cut-off proves to be the critical item. However, even the rel- ative magnitude may pose problems in analysis. Presumably, the number of fibers recruited is a function of the imposed loading. Consequently, a muscle might be expected to fire at different levels if it were active during both extension and retraction. Flipping of the tongue might well require less effort than, for instance, its retraction while lifting objects of varied mass.

Three lines of evidence may explain the contrast of constancy and variation. (1) The anticipatory firing during the preparatory phase seems to correlate with the toad's perception of prey. Toads sometimes move forward and then wait until more than one moving mealworm is adjacent; the tongue is then flicked to capture all at once. Apparently the variation of firing pattern relates to differences in the initial position of the tongue. (2) Quite regularly the $\mathrm{Mm}$. genioglossus basalis and medialis show a low-level pulse during the preparatory phase, prior to the much higher pulse observed during the tongue flip. We interpret this preliminary pulse as a positioning of the muscle fibers into the appropriate longitudinal relationships for the flip. Such preliminary standardization of the system presumably accounts for the low variability of EMGs observed among successive flips. (3) Variability during retraction and during the closing and post-closing periods apparently reflects the need for repositioning the flabby tongue and the prey.

The EMG could always be correlated with mechanical activity (in toads with body temperatures near $25^{\circ} \mathrm{C}$ ) following $5 \mathrm{msec}$ or less upon the signal. This is in good correlation with reports that mechanical activity in isometric contraction is temperature sensitive and occurs $5 \mathrm{msec}$ after stimulation at $20^{\circ} \mathrm{C}$ (Abbott and Brady, 1964).

\section{Mechanical synthesis of lingual protrusion}

The first series of events occurs during the preparatory phase and is clearly the anticipatory effect that bunches the lingual tissues near the mandibular symphysis and presumably orients the extensible soft tissue mass in anticipation of the flip. This bunching is also reported in cinefluorograms (Emerson, 1977). Low-level activity of the $M$. genioglossus medialis just before the flip seems to stiffen these long fibers into a rod.

The Mm. geniohyoideus medialis and lateralis would presumably act along a straight line between their origins on the symphysis and insertions on the hyoid. Even though the M. 
geniohyoideus medialis lies on the dorsal surface of the M. submentalis, neither it nor the M. geniohyoideus lateralis (which inserts near the lateral margin of the $M$. submentalis) would restrict deformation of $\mathbf{M}$. submentalis at the start of protrusion; the $M$. geniohyoideus medialis shows high-level activity only during late protrusion. While both $\mathrm{Mm}$. geniohyoidei assist in opening the mouth, the M. geniohyoideus lateralis also moves the hyoid plate anteriorly. This anterior movement reduces tension in the soft tissues that will be flipped (and thus allows their full and most rapid extension) and reduces the length to which the long, central fibers of the M. hyoglossus will be stretched (and with this improves the length-tension characteristics for its retraction). The low level of activity of the M. sternohyoideus fixes the hyoid, facilitating depression of the jaw by providing a stable origin for action of the M. geniohyoideus lateralis.

The major action of the $M$. geniohyoideus lateralis (but not the medialis) deserves attention, for not only does it move the hyoid anteriorly, but also adds a vector depressing the symphysis. In contrast, the lower level activity of this muscle during ventilatory oscillations appears to lack the depressing factor, and the contraction of the $M$. submentalis then lifts the mandibular symphysis (and the mentomeckelian bones, where unfused), and with this closes the nares (de Jongh and Gans, 1969).

Opening of the mouth apparently involves minor activity of the M. depressor mandibulae. In those flips in which the symphysial region starts bending ventrad as the mouth opens, one notes initial high levels of activity in the $\mathrm{Mm}$. submentalis and geniohyoideus lateralis; the $M$. genioglossus basalis fires at or within milliseconds before this interval. Apparently the M. submentalis acts to pull the mandibular tips together, thus deforming the mentomeckelian region and deflecting it ventrad so that there is an obvious bend of the tip of the jaws. The contraction of the M. geniohyoideus lateralis, acting as it does on the more lateral portion, provides further ventrad deformation of the symphysial zone. This anterior symphysial flexibility of Bufo marinus is apparently equivalent to the symphysial motility, which is in other species (Rana pipiens) induced by shifts of the mentomeckelian elements. The bending of the anterior zone is reduced as the mouth opens farther; i.e., a ventral shift of the posterior portion of the mandibles, due to action of the M. depressor mandibulae, follows, rather than precedes, downward deflection of the sym- physis. This supports the concept that the forces required for tha anterior bending must be applied near the symphysial region.

Coincident with this ventral bending, one sees the stiffened lingual rod lift from the floor of the mouth and rotate around and over the depressed mandibular symphysis (Fig. 3). The lingual rod is very clearly formed by the longfibered M. genioglossus medialis; the two rodshaped parts markedly increase in activity during the flip and are the only elements in a position to form this rod. What then rotates the lingual rod about the symphysis?

The basal rod is tied to the symphysial region and its anterior end and would be expected to be depressed as the symphysis is deformed ventrally (Fig. 3C). The activity of the very short fibered $M$. genioglossus basalis, which lies immediately deep to the lingual rod, would stiffen and thicken it, forming a transverse, rod-shaped mass between the mandibles, though this transverse rod would not induce transverse tension. Simultaneously, the more posteriorly positioned, short fibered, $\mathbf{M}$. submentalis forms a second rigid and transverse bar. Action of the Mm. submentalis and geniohyoideus lateralis induces symphysial depression; however, the M. submentalis does not itself move ventrally, but its mass shifts anteriorly and upward. When the M. submentalis is relaxed, its mass extends much further posteriorly than anteriorly between its two lateral attachments. Activation then brings the ends together, but also shifts the mass anteriorly; it changes the cross-section of the muscle from a horizontal to a vertical oval. The dorsal surface of the $M$. submentalis rises far above the level of the mandible and lifts the M. genioglossus basalis farther dorsally. While the anterior end of the rod formed by the $M$. submentalis is depressed, the slightly more posterior one is raised.

Combined EMG and cinematography indicate that the $M$. genioglossus medialis reaches high levels of activity and forms a rigid rod just after the activation of high-level activity of the Mm. submentalis and genioglossus basalis. Consequently, the rise of these two muscles exerts an upward force on the more posterior portion of the rod, and the depression of the mandibular symphysis exerts a downward force on its anterior portion. The resulting force-couple induces a strong moment that would then rotate the rod-shaped $M$. genioglossus medialis through $180^{\circ}$ around the mandibular symphysis.

Two factors induce the rapid rotation of the rod-shaped M. genioglossus medialis. First, the 
stiffness of the Mm. submentalis and genioglossus basalis reduces delay in the force transmission for producing movement. This stiffness greatly reduces any time lag due to initial compression of soft tissues. Secondly, these two rigid elements act near the point of rotation of the tongue. In a lever system, displacement closer to the fulcrum is amplified at the tip of the rotating arm. Consequently, elevation of the rigid M. submentalis, acting against a second rigid element (M. genioglossus basalis), produces simultaneous and marked rotation of the distal tip of the rigid lingual rod and rapidly protrudes the tongue.

The remaining soft tissues of the tongue, that were bunched anteriorly by the preparatory activity of the several muscles, are carried along by the rotational movement (Fig. 3C). They are accelerated as the rod lifts out of the buccal floor and tend to reach maximum acceleration by the time they pass the symphysial region. As the rod rotates farther (past $90^{\circ}$ ) its propalinal vector obviously becomes less, and the downward one increases.

Preparatory activity in the tongue has bunched it onto the tip of the rod, and the fluids in the central sinus have been shifted into the lingual base by action of the $\mathrm{Mm}$. geniohyoidei; this soft mass which was carried along by the lifting rod and is now propelled straight forward in a whiplash action due to the momentum entrained in its soft tissues (Fig. 3D).

As in a whip, the momentum is conserved and passes longitudinally through the soft tissues. The soft tissues of the anterodorsal surface of the tongue are apparently the first to reach their tensile limit and stop in an extended position. The orientation of the lingual surface shifts as the symphysis is crossed and the remaining portions of the inverted tongue continue their forward travel. It is interesting that they travel in an almost completely straight line that represents an anterior extension of the mandible and only slight depression below the mandibular level. The direction of the line of propulsion is indicated by the anteriormost extent of the genioglossal rod. If the tongue extends farther than one headlength, one can see this rod well defined in high-speed films. The more anterior portions of the tongue will then be narrowed beyond the zone of the M. genioglossus medialis up to the level at which the thickened lingual pad defines the end of the extended tongue. While its momentum causes this pad to deform around the surface upon which it impacts, there is little ventrad deformation below the level of the mandible. Indeed, in a number of flips in which toads were misled by prey seen in mirrors and the tongue never contacted a surface, the central rod always rotated $180^{\circ}$, and the soft tissues rotated slightly more. The tongue never continued to move and hit the ventral surface of the throat. Clearly, the rod remains rigid as it passes the symphysis and mainly imparts propalinal momentum; its more ventral component is retained as the soft tissues slip over its surface.

As the tongue straightens, so must its internal sinus and the initially folded M. hyoglossus; the fibers of this muscle come to lie in a more nearly straight line once the tongue has been fully extended. Activity of the Mm. geniohyoideus lateralis and medialis during the flip would presumably shift the hyoid anteriorly and subsequent activation of the $M$. sternohyoideus would stablize the hyoid, thus reducing the need for extension of the $M$. hyoglossus. As the tongue extends, the nerves and blood vessels flanking the central sinus also straighten from their complexly curved state.

\section{Mechanical synthesis of prey pick-up and lingual retraction}

If the tongue of the toad hits the prey appropriately, the lingual pad impacts so that the medial groove deforms around it (Fig. $3 \mathrm{E}$ and 4). The inertia of the lingual mass would tend to expel any air; good contact is then induced and the mucous contents of some of the intrinsic glands squeezed out. Adhesion of tongue and prey during retraction involves several factors. The fluid between tongue and prey not only is sticky, so that it will wet the surfaces contacted, but also has high viscosity and surface tension; thus, the bonds between tongue and prey will be maintained during retraction, and no air will enter the cavity between tongue and prey. The combination of stickiness and viscosity is clearly the critical item. Toads long have been known to have much more difficulty in ingesting moist objects, such as earthworms, than dry ones, such as beetles. The fluid-fluid interface provides a zone of discontinuity along which separation occurs. The serous secretion of the intermaxillary gland apparently does not participate in adhesion.

The major mass of the M. hyoglossus consists of long fibers that insert as a series of fascicles on the center of the lingual pad. The M. hyoglossus clearly initiates retraction, and it is 
likely that there is a differentiation of its activation time with the central fibers firing first. Films of flips that did not achieve full contact of prey onto substrate show a marked dimpling of the extended surface. This dimpling further suggests that there may be some central suction-effect, rather than a reliance on the properties of the fluid film. The detailed motor pattern within the M. hyoglossus clearly deserves more attention, as there is also the possibility of local feedback between sensors in the surface that contacts the prey and the underlying fascicles of this muscle.

Lingual movements are asymmetrical, and retraction is not an exact reversal of protraction. During retraction, contraction of the $M$. hyoglossus pulls the soft tissues of the extended tip posteriorly, while the basal rod remains rigid (note the low-amplitude and duration of activity of the $M$. genioglossus basalis and medialis during the beginning of retraction). Consequently, the portion of the tongue holding the prey has been repositioned deep in the buccal cavity, although much of the basal rod has not yet returned to the buccal cavity. Once the lingual pad passes the symphysis, activity in the M. genioglossus and in both the $\mathrm{Mm}$. geniohyoideus lateralis and medialis drops markedly. The basal mass starts to rotate, but then "melts" rather than rotating as a rigid element over the symphysial region.

The difference in their insertions explains the difference in actions of the $\mathrm{Mm}$. genioglossus and hyoglossus. Contraction of the M. genioglossus distalis should mainly pull the tongue to the symphysis, shortening and bunching it. The contraction of the M. hyoglossus would act primarily and directly on the region of the extended tip of the tongue and only secondarily upon its more basal portions. This action suggests that it is the basal portion of the tongue that would be lifted up and first rotated out of the mouth during protrusion, while the reversing action of the $M$. hyoglossus would initially affect the extended tip during retraction.

\section{Previous explanations}

The preceding results confirm the view expressed by Gaupp, Barclay, Magimel-Pellonier, Tatarinov, Severtzov, and Gans (among others) that the tongue is propelled and retracted directly by the action of intrinsic muscles, although the detailed mechanism developed represents a variant of those previously described. This may indeed reflect the diversity of species examined by these authors, as, for instance, the muscular arrangement in the tongue of ranids and bunfonids is quite distinct.

These present observations also confirm stimulation experiments indicating that the activity of the muscles attaching to the symphysial region is sufficient to flip the tongue. It is then unnecessary to invoke various levels of hydrostatic mechanisms (Hartog, 1901a, b). Fluids contained in the basal lymph sac might be displaced into the tongue during the contraction of the muscles of the buccal floor. Once there, they might be entrained during rotation and would then add to the mass of the tongue in the same way as does the sliding lead weight in special billies. However, such a role would be essentially passive; it would not produce the flip, nor do any of the photographs indicate that liquid is being returned.

Similarly, there is no evidence here for elastic recoil mechanisms involving the hyoid, in the version of either Gnanamuthu (1933) or Emerson (1977). It has been shown that the hyoid moves anteriorly during the flip and returns to its resting position during retraction. This return movement may indeed have an elastic component, although the retraction involves action of the $\mathrm{Mm}$. sternohyoideus and omohyoideus. However, the model of Emerson (1977) is clearly invalid, as the M. sternohyoideus shows only insignificant activity prior to, as well as during, the tongue flip; whereas the $M$. geniohyoideus lateralis (its antagonist) then shows high levels of activity. Thus the M. sternohyoideus does not retract and then release the hyoid at this time.

Furthermore, there is a fundamental difficulty with all propulsive mechanisms proposed for the hyoid of Bufo and Rana (but not for Rhinophrynus, Trueb and Gans, 1981). The hyoid is connected directly to the tongue only by the M. hyoglossus. Contraction of this muscle would draw the tongue posteriorly (and not bunch it as is seen prior to the flip). However, its relaxation could not induce forward momentum within the tongue unless (1) a second longitudinal muscle would then pull the tongue towards the symphysis, or (2) there were a mass of loose tissue that could be accelerated in order to transmit the momentum from hyoid to tongue. Neither condition is met. Also a recoil mechanism would not explain the stiffening and rotation of the basal portion of the tongue, nor its lifting from the buccal floor. Furthermore, the hyoid shift is much slower than the movement of the tongue. Finally, there is the observation that the tongue does 
not flip out and around the symphysis as a soft mass, nor does it tend to continue ventrally to contact the throat when prey is missed; rather one sees the firm skeleton of the rod rigidly extended toward the location of the prey.

The anterior and then posterior movements of the hyoid, the observation of which appears to have contributed substantially to the formation of the Emerson hypothesis, appear to reflect different factors and perhaps involve a different advantage. Hyoid movement just before and during the flip appears to be coincident with the contraction of the geniohyoid muscles that have (as proposed by Tatarinov, 1957) a major, but not a unique, component in symphysial depression. However, its anterior movement both reduces tension on the soft tissues during the flip (and thus allows full and most rapid extension) and reduces the length to which the hyoglossus will be stretched, and with this improves its length-tension characteristics.

\section{ACKNOWLEDGMENTS}

We are grateful to Mr. Mervin F. Roberts for use of the early photographs of tongue protrusion (originally commissioned and reproduced in part by Natural History magazine); to Dr. Max K. Hecht for loan of a Russian translation; to Dr. C. Schubert for permission to examine strobe photos of the flip in $B$. blombergi (Shubert, 1974); to R. Thomas and J. See for technical assistance; and to R. Marlow, R. A. Nussbaum, $O$. M. Sokol and L. Trueb for comments on the manuscript. Supported by NSF grant DEB-8003678 and DHEW grant PHS-G-IROIDE0511203.

\section{LITERATURE CITED}

Abbott, B. C., and A. J. Brady 1964 Amphibian muscle. In: Physiology of the Amphibia. J. A. Moore, ed. Academic Press, New York, Vol. 1, pp 329-369.

Alexander, T. R. 1964 Observation on the feeding behavior of Bufo marinus (Linné). Herpetologica, 20:255-259.

Barclay, O. R. 1942 Feeding of the common toad. Nature, 150:376.

Biesladecki, A. v., and A. Herzig 1859 Die verschiedenen Formen der quergestreiften Muskelfasern. Sber. k. Akad. Wiss. Wien., math. naturw. Kl., 33:146-149.

Böker, H. 1937 Einführung in die vergleichende Anatomie der Wirbeltiere. Vol. 2 (Die Biologie der Ernährung.). G Fischer, Jena.

Clark, R. D. 1974 Food habits of toad, genus Bufo (Amphibia: Bufonidae). Am. Midland Naturalist, 91:140-147.

de Jongh, H. J., and C. Gans 1969 On the mechanisms of respiration in the bullfrog Rana catesbeiana: A reassessment. J. Morph., 127:259-297.

Dugès, A. 1827 Rechèrches anatomiques et physiologiques sur la déglutition des reptiles. Am. Sci Nat., 12:337-345.

Dugès, A. 1834 Recherches sur l'osteologie et la myologie des batraciens à leurs différents àges. Mem. Acad. Roy. Sci. Inst. France, Sci. Math. Phys., 6:1-216.

Duméril, A. M. C., and G. Bibron 1841 Erpétologie générale et Histoire Naturelle des Reptiles. Roret, Paris, vol. 8.

Ecker, A. 1882 Die Anatomie des Frosches. Ein Handbuch für Physiologen, Ärzte und Studierende. F. Vieweg und Sohn, Braunschweig.

Emerson, S. 1977 Movement of the hyoid in frogs during feeding. Am. J. Anat., 149:115-120.

Ewert, J. P., I. Speckhart and W. Amelang 1970 Visuelle Inhibition und Exzitation im Beutefangverhalten der Erdkröte Bufo bufo (1). Z. vergl. Physiol., 68:84-110.

Ferdinand, L. 1894 Zur Anatomie der Zunge. Eine vergleichend-anatomische Studie. Munich.

Fischl, E., and R. H. Kahn 1928 Untersuchungen an einem Nerv-Muskel-Präparate zur Beobachtung einzelner quergestreifter Muskelfasern. Pflüger's Arch. ges. Physiol., 219:33-46.

Fixsen, C. 1857 De Linguae Raninae Textura Disquisitiones Microscopicae. Diss. inaug. Dorpati, Livonorum.

Francis, E. T. B. 1961 The sources and nature of salivary secretions in Amphibia. Proc. Zool. Soc. Lond., 136:453-478.

Fulton, G. P., and B. R. Lutz 1940 The neuro-motor mechanism in the small blood vessels of the frog. Science, 92:223-224.

Gans, C. 1961 The bullfrog and its prey. Nat. Hist., $70: 26-37$.

Gans, C. 1962 The tongue protrusion mechanism in Rana catesbeiana. Am. Zool., 2:524 (Abstract).

Gaupp, E. 1896 A. Ecker's und R. Wiedersheim's Anatomie des Frosches. Erste Abteilung. Vieweg, Braunschweig.

Gaupp, E. 1901 Ueber den Muskelmechanismus bei den Bewegungen der Froschzunge. Anat. Anz., 19:385-396.

Gelfan, S. 1930 Studies on single muscle fibers. I. The allor-none principle. Am. J. Physiol., 93:1-8.

Gnanamuthu, C.P. 1933 The anatomy of the tongue of Rana hexadactyla. Rec. Ind. Mus., 35:125-144.

Hartog, M. 1901a Sur le mécanisme de la propulsion de la langue chez les amphibiens anures. C. r. hebd. Acad. Sci. Paris, 132:588-589.

Hartog, M. $1901 \mathrm{~b}$ The mechanism of the protrusion of the tongue of the Anura. Preliminary note. Am. Mag. Nat. Hist. 7:501-503.

Holmes, S. J. 1906 The Biology of the Frog. Macmillan \& Co., New York.

Ingle, D. 1976 Behavior correlates of central visual function in Anurans. In: Frog Neurobiology. R. Llinas and W. Precht, eds. Springer Verlag, Berlin, pp. 435-451.

Klein, E. 1850 Beiträge zur Anatomie der ungeschwänzten Batrachier. Jahrb. Verein. väterl. Naturk. Württemberg 6:1-84.

Magimel-Pellonier, O. 1924 La Langue des Amphibiens (Anatomie et Ontogénie Comparées de la Forme et des Muscles). Thesis, Paris.

Noble, G. K. 1931 The Biology of the Amphibia. McGrawHill, New York.

Pratt, F. H., and M. A. Reid 1930 A method for working on the terminal nerve-muscle unit. Science, 72:431-433.

Regal, P., and C. Gans 1977 Functional aspects of the evolution of frog tongues. Evolution, 30:718-734.

Schubert, C. 1974 Behäbiger Riese mit schneller Zunge. Das Tier, 14:30-31, 68

Severtzov, A. S. 1961 On the mechanism of tongue protrusion in anuran amphibians. Doklad. Akad. Nauk SSSR. 140:(translation) $256-259$.

Tatarinov, L. P. 1957 Tongue movement mechanism in tailless Amphibia. Doklad. Akad. Nauk SSSR, 116:707-709 (Translation 916-918).

Trewavas, E. 1933 The hyoid and larynx of the Anura. Phil Trans. Roy. Soc. London B, 222:401-527.

Trueb, L., and C. Gans 1981 Tongue propulsion in Rhinophrynus: A mechanism unique in frogs. Am. Zool 21:970.

Waller, A. 1849 Minute structure of the papillae and nerves of the tongue of the frog and toad. Phil. Transact. London, 139.

Zug, G. R., and P. B. Zug 1979 The marine toad Bufo marinus: Natural history resume of native populations. Smithsonian Contrib. Zool., No. 284, 58 pp. 